\title{
An In Vitro Comparison of Shear Bond Strength Between Two Orthodontic Light-Curable Adhesive Pastes
}

\author{
Stephanie Becker \\ sebecker@mix.wvu.edu
}

Follow this and additional works at: https://researchrepository.wvu.edu/etd

Part of the Orthodontics and Orthodontology Commons

\section{Recommended Citation}

Becker, Stephanie, "An In Vitro Comparison of Shear Bond Strength Between Two Orthodontic LightCurable Adhesive Pastes" (2021). Graduate Theses, Dissertations, and Problem Reports. 8124. https://researchrepository.wvu.edu/etd/8124

This Thesis is protected by copyright and/or related rights. It has been brought to you by the The Research Repository @ WVU with permission from the rights-holder(s). You are free to use this Thesis in any way that is permitted by the copyright and related rights legislation that applies to your use. For other uses you must obtain permission from the rights-holder(s) directly, unless additional rights are indicated by a Creative Commons license in the record and/ or on the work itself. This Thesis has been accepted for inclusion in WVU Graduate Theses, Dissertations, and Problem Reports collection by an authorized administrator of The Research Repository @ WVU. For more information, please contact researchrepository@mail.wvu.edu. 
An In Vitro Comparison of Shear Bond Strength Between Two Orthodontic Light-Curable Adhesive Pastes

Stephanie Becker

Follow this and additional works at: https://researchrepository.wvu.edu/etd

Part of the Orthodontics and Orthodontology Commons 


\title{
An In Vitro Comparison of Shear Bond Strength Between Two Orthodontic Light-Curable Adhesive Pastes
}

\author{
Stephanie Becker, D.D.S. \\ Thesis submitted \\ to the School of Dentistry at \\ West Virginia University \\ in partial fulfillment of the requirements for the degree of \\ Master of Science in \\ Orthodontics
}

\author{
Chris Martin, D.D.S., M.S., Chair \\ Peter Ngan, D.M.D. \\ Elizabeth Kao, D.M.D., Co-Chair
}

Department of Orthodontics

Morgantown, West Virginia

2021

Keywords: shear bond strength, ARI, adhesive, BracePaste, Transbond XT

Copyright 2021 Stephanie Becker D.D.S. 


\title{
ABSTRACT \\ AN IN VITRO COMPARISON OF SHEAR BOND STRENGTH BETWEEN TWO ORTHODONTIC LIGHT-CURABLE ADHESIVE PASTES
}

\author{
Stephanie Becker
}

Background and Objectives: For today's busy orthodontist, it is critical to establish in-office bracket bonding procedures that are effective, time-saving, and error free. A relatively new light-cure orthodontic adhesive BracePaste ${ }^{\circledR}$ (American Orthodontics, Sheboyan, WI) can fluoresce under UV light to assist in cleaning up excess flash after bonding. Complete removal of excess resins around the bonded brackets may minimize excessive loss of enamel upon debonding. It is not clear in the literature if the utilization of a UV light system may compromise the bond strength between the bracket and enamel. The objective of this study was to determine the shear bond strength (SBS) of this new orthodontic adhesive "BracePaste" and compare it to the conventional "Transbond XT" adhesive (3M, St. Paul, MN). Additionally, the enamel bracket interface was examined to determine the location of bond failure and the tooth surfaces were examined to visually assess the severity of enamel marks and the presence of remaining adhesives on the enamel and brackets.

Materials and Methods: A sample of 84 extracted human premolars were randomly divided into two groups. Group 1 (control) American Orthodontics ${ }^{\mathrm{TM}}$ Low Profile metal twin brackets were bonded with the Transbond ${ }^{\mathrm{TM}}$ XT composite resin; Group 2 brackets were bonded with Bracepaste ${ }^{\circledR}$ composite resin. All samples were etched with $37 \%$ phosphoric acid, rinsed with distilled water, dried, applied with a layer of Assure Plus resin, and then composite resin. All bonded brackets were placed in a thermocycler for 24 hours cycling between baths of $5^{\circ} \mathrm{C}$ and $55^{\circ} \mathrm{C}$. After thermocycling, the brackets were debonded from the teeth with an Instron machine (crosshead speed $1 \mathrm{~mm} / \mathrm{min}$ ) simulating and calculating debond shear force. The bracket and tooth were examined under 10x magnification to determine the adhesive remnant index (ARI) value using a 4-point and 6-point scale. Then, a Visual Index scale was used to measure enamel marks on teeth after finishing and polishing. Two independent sample $t$ tests were used to compare the difference in mean SBS between both groups. Exact Mantel-Haenszel chi-square analysis was conducted to assess the association between ARI value and group. We considered statistical significance for all tests with a two-sided p-value of $\leq 0.05$.

Results: The final sample consisted of 33 premolars bonded with Transbond XT and 39 bonded with BracePaste. There was no significant difference in mean SBS between the teeth bonded with Transbond $\mathrm{XT}(\mathrm{M}=16.8 \mathrm{MPa}, \mathrm{SD}=7.2)$ or BracePaste $(\mathrm{M}=14.9 \mathrm{MPa}, \mathrm{SD}=6.4)(\mathrm{t}(70)=1.2, \mathrm{p}=0.23)$. No significant differences were found in the ARI scores between the 2 groups using either the 4 point $\left(\chi_{\text {MH }}^{2}(1)=0.85\right.$, $\mathrm{p}=0.36)$ or 6 point $\left(\chi_{\mathrm{MH}}^{2}(1)=0.25, \mathrm{p}=0.62\right)$ ARI scoring systems. Out of 52 teeth scored with the 4 point ARI system values of 1 or 2 , there was no significant difference in adhesive remnants left after polishing between the 2 groups of brackets $\left(\chi^{2}{ }_{\mathrm{MH}}(1)=0.21, \mathrm{p}=0.71\right)$, using a Visual Index scale.

Conclusions: The new BracePaste composite resin possessed similar SBS to the conventional Transbond $\mathrm{XT}$ resin and both are able to withstand occlusal forces during orthodontic treatment. The addition of the UV light system with the new composite resin did not compromise the bond strength or result in more enamel defects after debonding and finishing. 


\section{DEDICATION}

To Mom, Dad, and Scott: Thank you for your endless love and support every single day. You have always believed in me, encouraged me, and I could not have gotten here without you. I am eternally grateful that I get to have you as my family. I love you! 


\section{ACKNOWLEDGEMENTS}

Dr. Ngan, Thank you for believing in me and allowing me the avenue to achieve my dream of becoming an orthodontist. I am so grateful for all of your guidance and support over the past three years!

Dr. Martin, You have been a rock for the residents, always there to teach us and guide us in everything you know about orthodontics. Thank you for being so reliable and always there to lend a helping hand. I felt so supported by you in clinic and in my research. You are appreciated more than you can imagine!

Dr. Kao, Your passion for research is unparalleled. Thank you for your continued guidance and dedication to my research. I am so grateful for all the time and energy you invested in me!

Vince Kish, Thank you for your wisdom and expertise, especially in regards to the Instron machine. You were a pleasure to work with and this project came to fruition largely due to your efforts!

Jun, Thank you for your tireless efforts in helping me to complete my research project. I would have been lost without all of your guidance and I appreciate you so much!

Carl, Niki, Joanna, Sarah, Minh, Dustin, Your friendship means the world to me, and when I think of my favorite thing about this program, it was getting to have you as my coresidents. You have all taught me so much, about life and orthodontics, and I am so grateful that I got to share this experience with you. Thank you for all of the never-ending support and helping me to get to where I am today!

Miranda, Justin, Sharon, Nick, Rachel, Ian, Thank you for all the fun and laughs we have had together! Even though COVID took away our trips, hanging out with you all in the resident room was a blast! I am so glad that I got to have such supportive, caring coresidents who lift each other up and make each other better! Best of luck on the rest of your residency journey; I will be cheering you on from South Carolina.

Marsha, Donna, Leslee, Thank you for taking such good care of us as we made our way through clinic. You were always available with a helping hand or listening ear (or a sassy joke....Donna!), and this program would not have been the same without you.

Dr. Cyterski, I am so grateful that you took me on as your mentee! I will never forget how you were the only orthodontist in the area to respond to my letter inquiring about shadowing and from there, you took me under your wing and helped guide me through undergrad, dental school, and my residency. I have looked up to you since we met and I am excited to continue learning from you and bouncing ideas off of you; thank you for being such a wonderful friend!

Logan, From the moment we met, you have been such a source of positivity, light, love and encouragement and I feel incredibly lucky that I came here for residency, because it led me to you. Thank you for your constant support and encouragement, I love you! 


\section{TABLE OF CONTENTS}

\section{Table of Contents}

ABSTRACT

ACKNOWLEDGMENTS................................................................................................... iii

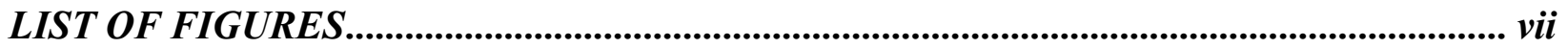

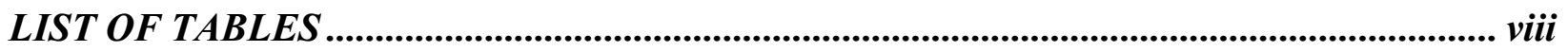

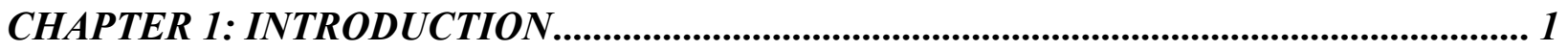

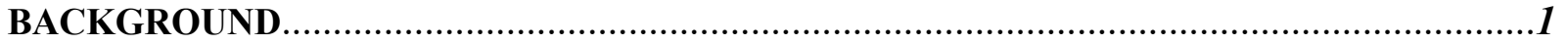

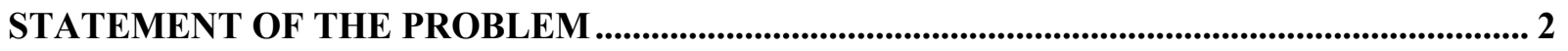

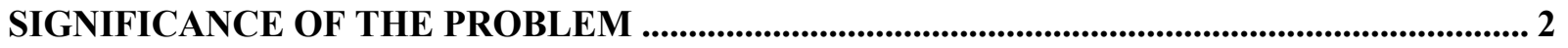

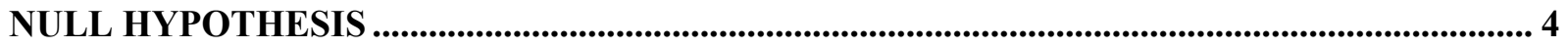

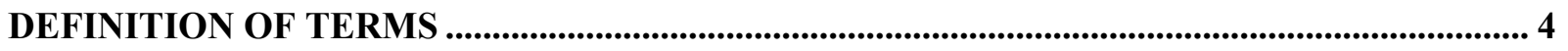

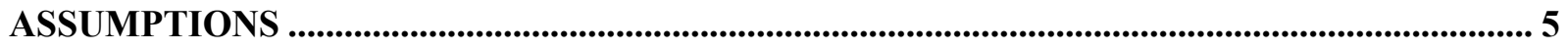

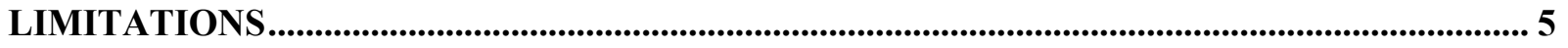

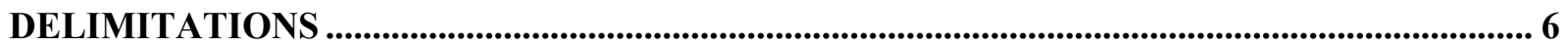

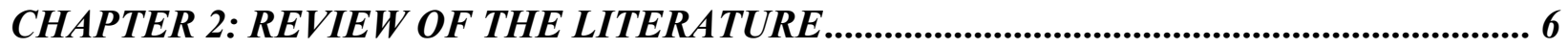

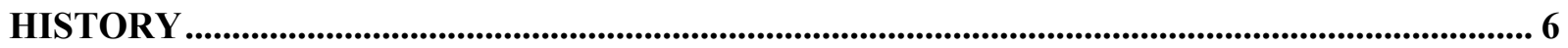

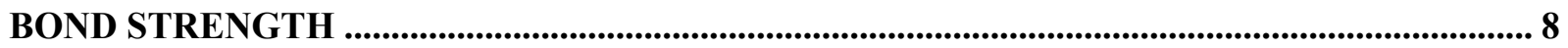

IN VITRO LITERATURE REVIEW .................................................................................................. 9

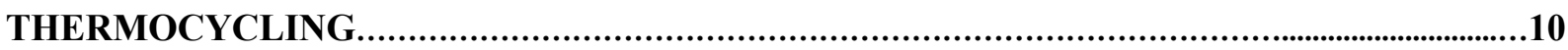

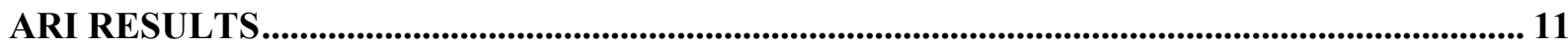

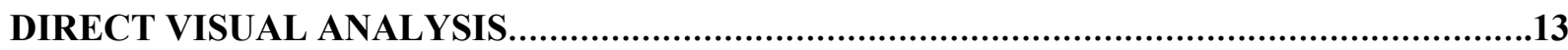

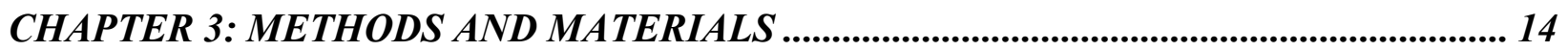

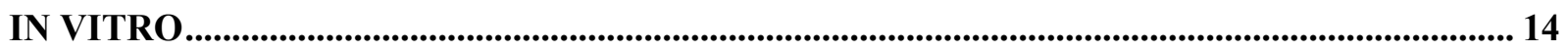

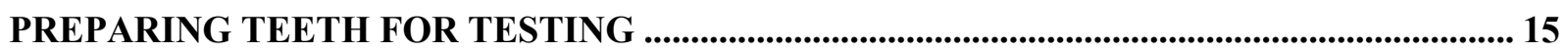

BONDING PROCEDURES............................................................16

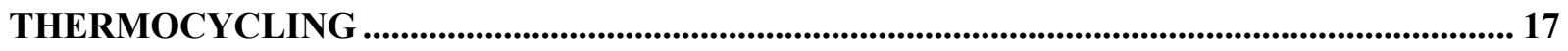

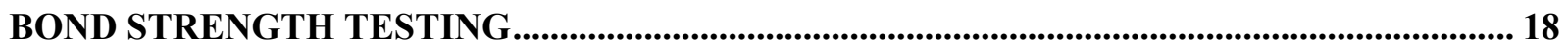

ADHESIVE REMNANT INDEX (ARI) MICROSCOPY ............................................................. 19

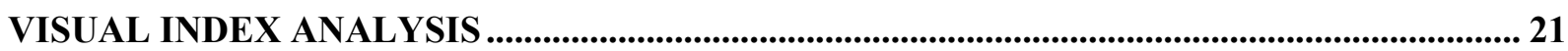

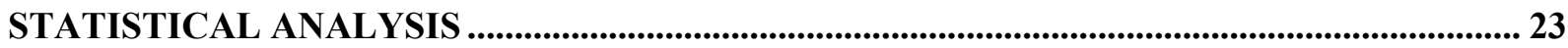

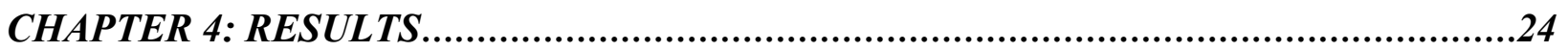




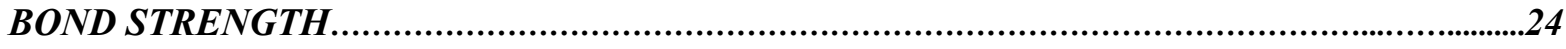

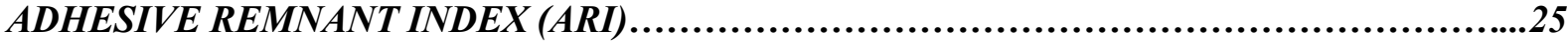

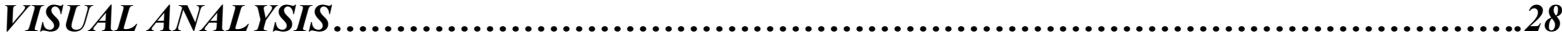

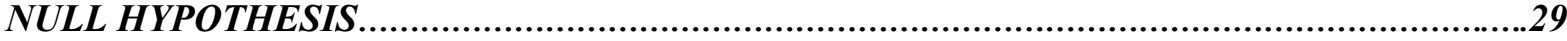

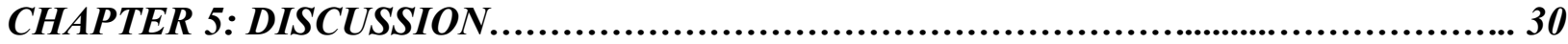

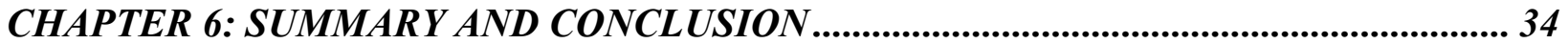

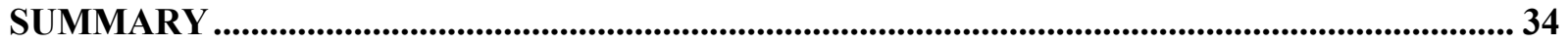

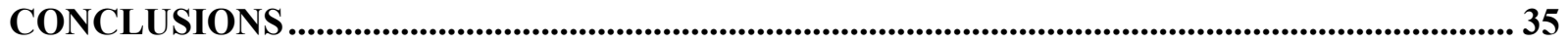

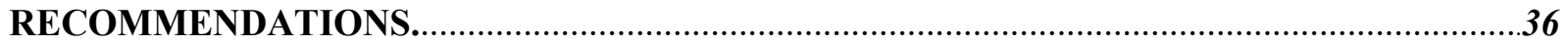

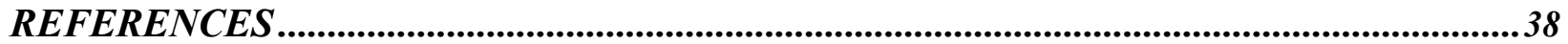

APPENDICES

APPENDIX A-IRB APPROVAL LETTER.............................................42

APPENDIX B-DATA RESULTS...................................................44 


\section{LIST OF FIGURES}

Figure 1: Stainless steel rings with wax base prior to potting premolars................................15

Figure 2: Epoxy resin for tooth mounting........................................................ 15

Figure 3: Premolar potted in stainless steel ring prior to testing ......................................... 16

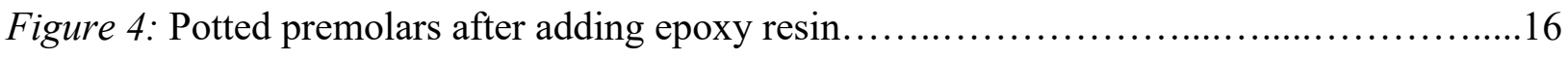

Figure 5: Thermocycler bath loaded with test samples ..................................................18

Figure 6: Instron Universal Testing machine..................................................................... 19

Figure 7: Sample ready for testing in Instron.................................................................. 19

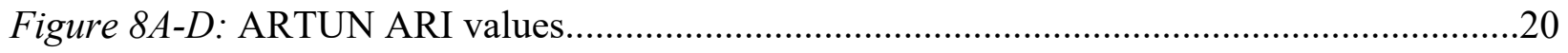

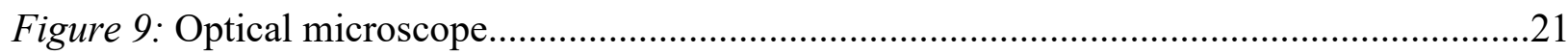

Figure 10: Teeth visualized under UV and ambient lighting............................................22

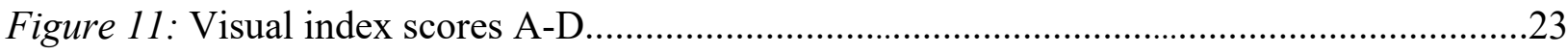

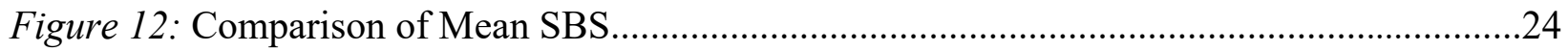

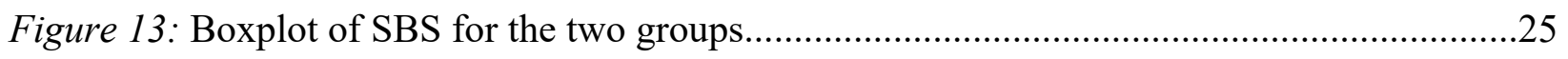




\section{LIST OF TABLES}

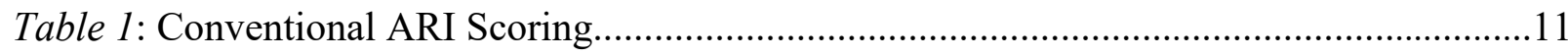

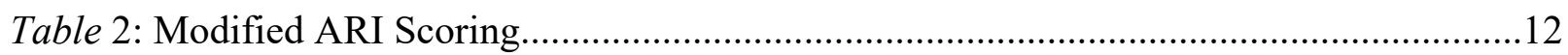

Table 3: Comparison of mean SBS....................................................................................24

Table 4: Comparison of mean SBS between ARI (6-point scale) scores................................26

Table 5: Comparison of mean SBS between ARI (4-point scale) scores................................26

Table 6: Average ARI scores for BracePaste and Transbond XT......................................27

Table 7A-B: ARI distribution by percentage................................................................27

Table 8: Direct Visual Analysis Comparison between adhesives...........................................28 


\section{CHAPTER 1: INTRODUCTION}

\section{BACKGROUND}

For today's busy orthodontist, it is critical to establish treatment procedures that are as effective, time-saving and error-free as possible. Not only does this save the orthodontist's time and money, this also reduces patient chair time and potential extra visits. Brackets that fracture off easily may lead to an inconvenience to the orthodontist and patient, and an increased financial cost to the patient. One particular area within orthodontic treatment that orthodontists have control over is the choice of bonding system they use for direct bonding.

The company American Orthodontics developed BracePaste ${ }^{\circledR}$ Adhesive as an attempt to establish a medium viscosity, light-curable adhesive that provides optimum bonding to metal brackets, allows immediate tie-in after light curing, and fluoresces under UV light to assist in clean up. The removal of attachments and all adhesive resin from tooth surfaces without iatrogenic damage is the main objective of bracket debonding. Improper debonding techniques can cause enamel damage and be more time-consuming, so use of UV light to visualize BracePaste remnants could potentially help cut down on the excessive loss of enamel. With the utilization of a UV light system, the operator would be able to better distinguish the visual difference between adhesive material and enamel surface as opposed to an adhesive that does not fluoresce under UV. Thus, this aids in the preservation of precious enamel when using this new type of adhesive.

Another purpose of this study is to determine if BracePaste ${ }^{\circledR}$ Adhesive has comparable bond strength as the gold standard adhesive, Transbond XT Adhesive when used with conventional bonding procedures, consisting of 37\% phosphoric acid etc, primer (Assure Plus), 
then adhesive. After orthodontic brackets are debonded, Adhesive Remnant Index (ARI) will be scored on each tooth-bracket interface. The purpose of using this index is to determine the location of the remaining adhesive after a bracket is debonded, and how much is on the tooth as opposed to the bracket. This will help identify which sort of bond failure occurred, cohesive or adhesive. After ARI values have been scored, adhesive remanants (AR) will be removed with finishing and polishing. Then, the tooth surfaces will be examined under a 10x microscope to visually assess the severity (if any) of enamel marks and if any adhesive still remains.

\section{STATEMENT OF THE PROBLEM}

1. Does BracePaste ${ }^{\circledR}$ Adhesive have comparable in-vitro SBS as Transbond XT Adhesive when used with conventional bonding procedures?

2. What are the characteristics of bracket failure interface when examined under optical microscopy and scored with both modified and conventional ARI values?

3. Does the use of UV light as an aid in AR removal lead to more significant enamel defects in teeth that are finished/polishing using this method as opposed to the standard protocol?

\section{SIGNIFICANCE OF THE PROBLEM}

Composite resin is the adhesive of choice for orthodontists when bonding brackets. Brackets that break off easily may cause damage to the teeth, leading to inconveniences for the orthodontist and patient, and increased financial cost to orthodontist and to patient. ${ }^{1}$ So, resin with an appropriate bond strength is a must, but furthermore, the adhesive must be removed completely with the goal of preserving the enamel as close as possible to its original condition. Composite resin is an ideal adhesive as the margin between the enamel and resin is hard to 
detect, which provides appropriate esthetics. BracePaste ${ }^{\circledR}$ is unique in that this product fluoresces under UV light, which allows adhesive remnants to be seen for easier removal so that none is missed. It is critical for resin to be completely removed as failure to do so can promote dental plaque accumulation along the residual resin interface. This increases the risk of enamel surface decalcification and caries lesion development and progression. ${ }^{2}$ Difficulty in detection of the enamel-resin margin can lead to failure in removal of all remaining resin post-debond. Difficulty in the detection of resin is especially prevalent in posterior teeth, where there is reduced accessibility and visualization. Molars present a large surface area for bonding, so with reduced accessibility to these teeth, it creates a greater challenge of removing AR after debond. ${ }^{3}$ The issue of bonding remnants being found after orthodontic bracket removal is such an established issue that visual inspecting indices for determining resin remnant prevalence after debond, such as the adhesive remnant index (ARI) and modiefied ARI are used. ${ }^{4}$ Additionally, bonding remnants on the tooth surface after debond can discolor over time, leading to patient dissatisfaction. Futhermore, there is the potential for less enamel damage when using BracePaste for the same reason; UV light once again allows a better visualization of the remaining resin on the tooth. It has been reported that resin remnant removal has an average loss of $55 \mu \mathrm{m}$ of enamel per tooth, thus a technique that can reduce or eliminate this should be highly considered. ${ }^{5}$ Many techniques have been formulated with the purpose of removing AR after orthodontic debond, and these result in varying degrees of abrasion and enamel loss. ${ }^{6,7}$ To minimize the enamel defects and abrasion after debonding, a protocol that spares enamel while still performing efficiently and effectively should strongly be considered. It was noted in Schott's paper that, "According to the principles of good clinical practice, all available means for better diagnostics and treatment should be utilized". ${ }^{8}$ So, traditional methods of finishing using conventional ambient light may 
no longer be considered as sufficient standard protocol if a protocol utilizing UV light provides efficacious results.

\section{NULL HYPOTHESIS}

1. There is no significant difference between the SBS of "BracePaste" and "Transbond XT".

2. There is no significant difference in mean SBS between the different degrees of ARI scores.

3. There is no significant difference in the amount of enamel removal marks using the visual index analysis between "BracePaste" and "Transbond XT".

\section{DEFINITION OF TERMS}

1. Composite resin: An adhesive that consists of a polymer base resin and inorganic filler material. Coupling agents are often used to chemically bond these constituents together.

2. Enamel: the normally visible part of the tooth, covering the crown, a very hard, white to offwhite, highly mineralized substance that acts as a barrier to protect the tooth but can become susceptible to degradation, especially by acids from food and drink

3. Phosphoric Acid: the use of an acidic substance to prepare the tooth's natural enamel for the application of an adhesive. The acid roughens the surface microscopically, increasing retention of resin sealant.

4. Bonding Materials: A term used to indicate supplies that attach the orthodontic brackets onto teeth. Synonyms: bonding adhesives, orthodontic adhesives, Trasbond XT, BracePaste

5. Transbond XT: A light curable bonding adhesive/paste for orthodontic brackets that is deemed the gold standard for orthodontic bonding. 
6. BracePaste $^{\circledR}$ : A light curable bonding adhesive/paste for orthodontic brackets that fluoresces under UV light for easier removal from tooth.

7. Shear Bond Strength: Stress required to separate a bonded bracket from a tooth when on portion is forced to slider over another portion.

8. Fixed Appliance: An orthodontic material that has attachments which are bonded or cemented to the teeth that are not removable.

9. Adhesive Remnant: adhesive left on the tooth after debracketing

\section{ASSUMPTIONS}

1. There is one operator, S.B., who has clinical experience and has trained in precise bracket placement and bonding procedures.

2. The bracket base of each bracket is assumed to be accurate with the measurements provided from lab measurements and each bracket is consistent with the estimated measurement.

3. Brackets are to be bonded in the same location, the buccal height of contour, of permanent premolars with the same amount of force.

\section{LIMITATIONS}

1. This in-vitro testing environment differs from the in-vivo testing environment as in-vitro testing cannot exactly simulate the environment of the oral cavity.

2. Forces applied by the Instron (Instron Corp., Canton, MA) mechanical testing machine will simulate a peel and shear force rather than that of a pure shear force.

3. Extracted teeth may vary in mineral content, history of abrasion, surface contour, fluoride content, hypocalcification, carious lesions, and dental restorations. 
4. Evaluation of residual resin remaining and enamel surface irregularity after debonding is subjective and can be inconsistent.

\section{DELIMITATIONS}

1. Samples will be limited to extracted permanent maxillary and mandibular premolars and they will be stored in a 1:1:1 water, glycerol, bleach mixture.

2. Low-profile premolar brackets will be bonded to sound enamel with consistent force.

3. One operator will perform the bonding, debonding, and finishing procedures.

4. Two operators, S.B., and E.K., will be calibrated for precise ARI and visual analysis measurements.

5. Only two types of bonding adhesives will be studied, both with the same bonding protocol, and performed by a single operator, S.B.

6. Thermocycling for 24 hours between $5^{\circ} \mathrm{C}$ and $55^{\circ} \mathrm{C}$ will be used to simulate clinical conditions. 


\section{CHAPTER 2: REVIEW OF THE LITERATURE}

\section{HISTORY}

During the early days of fixed-appliance orthodontic treatment, brackets were not bonded to teeth. Rather, they were welded to gold or stainless-steel bands, which required a timeconsuming application process that was uncomfortable for the patient. ${ }^{9}$ Furthermore, these banded appliances frequently caused gingival trauma when fitted, and decalcification could occur under the band if the cement failed; thus, this system was far from ideal.

A critical development in the practice of dentistry that has evolved over the course of the past century has been the use of composite resins, especially in regard to the creation and evolution of light- cure resins. One particular area within orthodontic treatment that the orthodontist has control over is the choice of their bonding system for direct bonding. Newman originally built upon Buonocore's innovative enamel acid etching technique for the purpose of direct bonding plastic attachments (polycarbonate brackets) to the buccal surfaces of the teeth. ${ }^{10}$ The first orthodontic bonding resins relied on chemical cure to polymerize. These types of resins presented a problem in that their setting time could not be manipulated and thus clinically very technique sensitive. ${ }^{11}$ Even though chemical-cure resins have been shown to have a similar bracket debond rate compared to light-cure resins, setting time limitations have contributed to their decline in popularity. ${ }^{12}$ In direct bonding technique, the composite resin is cured under metal-based brackets by direct illumination from different sides and by transillumination through the tooth structure. Rapid polymerization occurs when visible light is applied and the resin then adheres to the tooth, chemically and mechanically. Ideally, this bond should be strong enough to withstand masticatory forces. Having clinically acceptable strength will help with longevity of the bracket bond to the tooth and cut down on emergency appointments for lost brackets. ${ }^{13}$ 


\section{BOND STRENGTH}

Bond strength is defined as the initial mechanical load to fracture divided by the simple, geometrically defined, cross-sectional area of the bond. ${ }^{14}$ Previous studies have measured the debonding force by using an Instron universal testing machine and shear bond strength (MPa) was calculated by dividing debonding force by bonding area. ${ }^{15}$ For bonding to enamel, Gillis suggested SBS should fall in the range of 4-10MPA. ${ }^{16}$ Brantley and Eliades found that for fixed appliance therapy, conventional adhesive systems on enamel ranged between 8- 30 MPA of SBS. ${ }^{17}$ This bond must be able to withstand the masticatory forces of the moist oral environment as well as the variable forces in orthodontic treatment, so testing new adhesive products is essential in order to find out the effectiveness of the new material.

The demand for esthetics has driven bracket manufacturers to produce smaller and less visible appliances, putting additional stress on the adhesive. Therefore, the ideal adhesive of the future would be hydrophilic, would not require acid etching of the enamel, and would have a SBS value of over $20 \mathrm{MPa}$ in both dry and wet fields, according to a review by Gange. ${ }^{9}$ While Transbond XT does require acid etching, it is hydrophilic, satisfying some of the requirements of an ideal adhesive. As the field of adhesive dental materials evolves, it is critical to keep up with the latest developments in this area and perform the necessary research to assure a satisfactory bonding effectiveness. Researchers previously had commonly performed in vivo SBS tests on human third molars, however, these teeth are much more permeable in a wetter environment than erupted teeth so they may not be the ideal choice for bond testing. ${ }^{14}$ Ozturk found that both tooth type and adhesive had a significant effect on SBS with no significant differences between the bond strength values for upper and lower teeth. He also found that there were differences in bond 
strength values of teeth in the upper and lower arches for some tooth types. ${ }^{18}$ Hence, when involved in SBS testing, it is wise to use the same tooth type from the upper or lower arch. So, this study was limited to permanent premolars to help increase consistency of results.

\section{LITERATURE REVIEW (IN-VITRO)}

Many studies have analyzed SBS among an abundance of bonding agents on metal brackets, however, only one study has assessed the SBS of BracePaste. Shams studied extracted maxillary central incisors to measure the difference in SBS between Transbond XT and BracePaste, finding a significantly lower SBS for BracePaste (187.4N) as compared to Transbond XT $(233.34 \mathrm{~N}) \cdot{ }^{19}$ As for the adhesive materials, both Transbond XT (3M) and BracePaste Medium Viscosity (American Ortho) are light cure adhesives meant for the bonding of metal and ceramic brackets. Transbond XT has a makeup of 45-55\% BisGMA, 45-55\% TEGDMA, and $<0.5 \%$ 4-(Dimethylamino)-Benzeneethanol, while BracePaste's full composition is not released. However, ethoxylated bisphenol A dimethacrylate, tetramethylene dimethacrylate, diphenyl(2, 4, 6-trimethylbenzoyl) phosphine oxide are listed as ingredients that makeup about $10 \%$ of BracePaste's composition. Since different adhesives have been shown to have different effects on SBS, the primer for both experimental groups should remain the same. 3M claims to have the "gold standard" in terms of orthodontic bonding systems, so as limited prior research has been published about BracePaste, this research study can compare the new adhesive to the existing "gold standard" to assess for efficacy. Another goal of orthodontic adhesives is to achieve an adequate bond, meaning the failure occurs at the enamel-composite interface. This would be desirable because debonding and subsequent polishing would become much easier because much of the composite has already debonded from the tooth. Previous 
research has found that the SBS of Transbond XT Adhesive (with Transbond XT Primer) had a mean SBS of $14.49 \mathrm{MPa} .{ }^{20}$ Thus, it has an adequate bond strength and can serve as a control. Currently, there are no published SBS values for BracePaste recorded in MPa units, so this orthodontic adhesive will be compared to Transbond XT.

The demand for optimal esthetics has driven orthodontic bracket manufactures to produce small and less visible brackets, hence the low-profile style of bracket. ${ }^{9}$ While this type of bracket is indeed less conspicuous than the standard variety, the smaller bracket base leads to excess stress being placed onto the tooth-adhesive interface. So, as orthodontic technology advances, it is important that the adhesive resins are able to maintain a clinically acceptable bond strength.

\section{THERMOCYCLING}

A goal of all research studies is to strive for as much clinical relevance as possible. Thus, when analyzing extracted teeth in vitro, thermocycling is a technique that can be used to better simulate the oral environment and improve the quality of the research. The oral cavity routinely exposes orthodontic adhesives not only to temperature variations, but also humidity and air velocity when breathing, which in turn can alter the resting mouth temperature. ${ }^{21}$ These temperature variations are unpredictable but it is crucial to determine if they induce stress into the adhesive that may impact its bond strength. For this reason, Bishara et al suggested that thermocycling is a critical component of the testing protocol for new adhesives. ${ }^{22}$ The thermocycling technique allows the researcher to simulate the oral environment by cycling teeth which have already been bonded through water baths with temperatures ranging from $5^{\circ} \mathrm{C}$ to $55^{\circ} \mathrm{C} .{ }^{23-24}$ Daub et al. found that thermocycling does indeed have an effect on SBS values. In one of his test groups, he bonded premolars with Transbond XT and each sample was thermocycled 
between 5 degrees $\mathrm{C}$ and 55 degrees $\mathrm{C}$ for 500 cycles. Whenever he compared the SBS from each of these samples to that of a previous study using the same protocol, but without thermocycler use, he found that the SBS was reduced significantly in his samples $(p=0.001) .{ }^{25}$ Other previous studies have also reported a decrease in bond strength when thermocycling protocol was depoloyed. ${ }^{26,27}$ Thus, the clinical relevance of thermocycling is that studies have shown that thermal stresses reduced mean bond strength in orthodontic adhesives. This implies that thermal stresses encountered in the mouth may also play a role in lowering bond strength values. However, one must remember that these in-vitro results may not be extrapolated exactly into an in-vivo environment as samples thermocycled in water do not fully replicate the challenging environments in the oral cavity. It does, however, come closer than if no thermocycling is introduced.

\section{ADHESIVE REMANANT INDEX RESULTS}

Adhesive Remnant Index (ARI) is an analysis used to measure bond failure after shear bond strength testing by assessing how much adhesive is left on a tooth after a bracket has been debonded. Artun and Bergland ${ }^{28}$ developed this system, which consists of four scoring categories, 0 to 3. Each category is described below:

\begin{tabular}{|l|l|}
\hline SCORE & DEFINITION \\
\hline 0 & No adhesive remaining on the tooth \\
\hline 1 & Less than half of the adhesive left on the tooth \\
\hline 2 & All adhesive remaining on the tooth \\
\hline 3
\end{tabular}

Table 1. Convention ARI Scoring (in relation to the tooth) 
This four-point scale was used in this study to determine where the resin bond debonded from the perspective of the tooth.

A modified ARI scale ${ }^{29}$ was also used to measure the amount of adhesive left on the bracket, as this system allows for a more specific reading of residual remnant amount and location.

\begin{tabular}{|l|l|}
\hline Score & Definition \\
\hline 0 & No adhesive left on the bracket \\
\hline 1 & $1 \%-25 \%$ of adhesive left on the bracket \\
\hline 2 & $26 \%-50 \%$ of adhesive left on the bracket \\
\hline 3 & $51 \%-75 \%$ of adhesive left on the bracket \\
\hline 4 & $76-99 \%$ of adhesive left on the bracket \\
\hline 5 & All adhesive left on the bracket with distinct impression of bracket mesh \\
\hline
\end{tabular}

Table 2. Modified ARI Scoring (in relation to the bracket)

Cehreli et al found that qualitative visual scoring, ARI measurements, is capable of generating similar results with both SEM analysis and elemental mapping, and thus is an effective method of evaluating adhesive remnant amounts and locations. ${ }^{30}$ Kaneshima et al also found that when assessing adhesive remnant removal, SEM and visual analyses did not yield significantly different results. ${ }^{31}$ As ARI scores are interpreted, it is important to keep in mind the implications of the different surfaces the scores are made on relative to tooth or bracket. For example, a low ARI score suggests a reduced risk of enamel tear, which would be beneficial to the patient. This is due to less adhesive being left on the bracket and more adhesive on the tooth. A high modified ARI score, on the other hand, may be favorable in the sense that chairside time spent removing adhesive remnants would likely be reduced due to the less amount of residual resin left on the tooth and more on the bracket. 
In relation to bond strength, Mirzakouchaki et al. stated that the changes in bond strengths are parallel with the changes in the ARI index. ${ }^{24}$ The greater the bond strength the more likelihood there will be more adhesive left on tooth enamel than if there is weaker bond strength. This would imply a greater amount of time is necessary chairside in removing adhesive remnants after debonding.

\section{DIRECT VISUAL ANALYSIS}

Direct visual analysis is used to examine the enamel surface under a light using the naked eye to simulate visualizing a tooth surface in a clinical setting. ${ }^{31}$ This is done after performing adhesive remnant removal and subsequent finishing and polishing of the tooth surface.

Kaneshima et al created a criterion for direct visual analysis which consists of four categories of teeth:
A. Absence of removal marks
B. Presence of soft removal marks
C. Presence of more evident removal marks
D. Presence of adhesive remnants

When using a two-examiner team to perform this assessment, calibration is necessary before the examiners may perform individual assessments. These assessments then can be used to create a joint analysis of the samples by obtaining a group consensus. ${ }^{31}$ An optical microscope at 10x magnification was used in this study for better visualization of tooth surfaces. 


\section{CHAPTER 3: MATERIALS AND METHODS}

\section{IN-VITRO STUDY}

This chapter describes the samples, methods of data collection, statistical analysis, materials, and equipment that were used in the in vitro study. Eighty-four human permanent maxillary and mandibular premolars were collected to study the SBS of Master Series ${ }^{\circledR}$ metal twin low-profile brackets (American Orthodontics, Sheboygan, WI) with two different bonding adhesives: Transbond XT (3M Unitek, Monrovia, CA) or BracePaste ${ }^{\circledR}$ (American Orthodontics, Sheboygan, WI). The criteria for tooth selection includes non-carious teeth with an intact facial surface and no visible cracks in the enamel. The teeth were cleaned of debris, steam autoclaved, pumiced with non-fluoridated prophy paste and stored in a 1:1:1 mixture of bleach, glycerol, and water. The eighty-four human permanent premolars were randomly divided into two groups based on the bonding protocol. The groups are as follows:

Group 1 (Control Group): 42 mounted teeth were orthodontically bracketed with 37\% phosphoric acid etch (MARK3), AssurePlus primer, Transbond ${ }^{\mathrm{TM}}$ XT Light Cure Paste Adhesive (3M Unitek, Monrovia, CA), then Master Series ${ }^{\circledR}$ metal twin low-profile brackets (American Orthodontics, Sheboygan, WI).

Group 2: 42 mounted teeth were orthodontically bracketed with 37\% phosphoric acid etch (MARK3), AssurePlus primer, BracePaste ${ }^{\circledR}$ (American Orthodontics, Sheboygan, WI), and Master Series ${ }^{\circledR}$ metal twin low-profile brackets (American Orthodontics, Sheboygan, WI). 


\section{PREPARING TEETH FOR TESTING}

Prior to testing, the tooth apex was flattened with a dental handpiece by $3-5 \mathrm{~mm}$, allowing the CEJ to sit above the stainless steel potting ring by about $2-3 \mathrm{~mm}$. Then, a hole was drilled through each tooth approximately $5 \mathrm{~mm}$ from this new apex. A 0.040 stainless steel wire was placed through each hole for additional retention when mounted in the epoxy resin (Buehler, Lake Bluff, IL). Wax was fitted to the base of round stainless-steel potting rings in order to prevent leakage of the epoxy resin. The teeth were embedded in epoxy resin up to the cementoenamel junction in stainless steel rings. ${ }^{32}$ The teeth were stored in water until bonding brackets to the facial surface. Brackets were positioned with the aid of a dental surveyor so that bracket bases would be parallel to the buccal surface of the tooth and with consistent loading force.

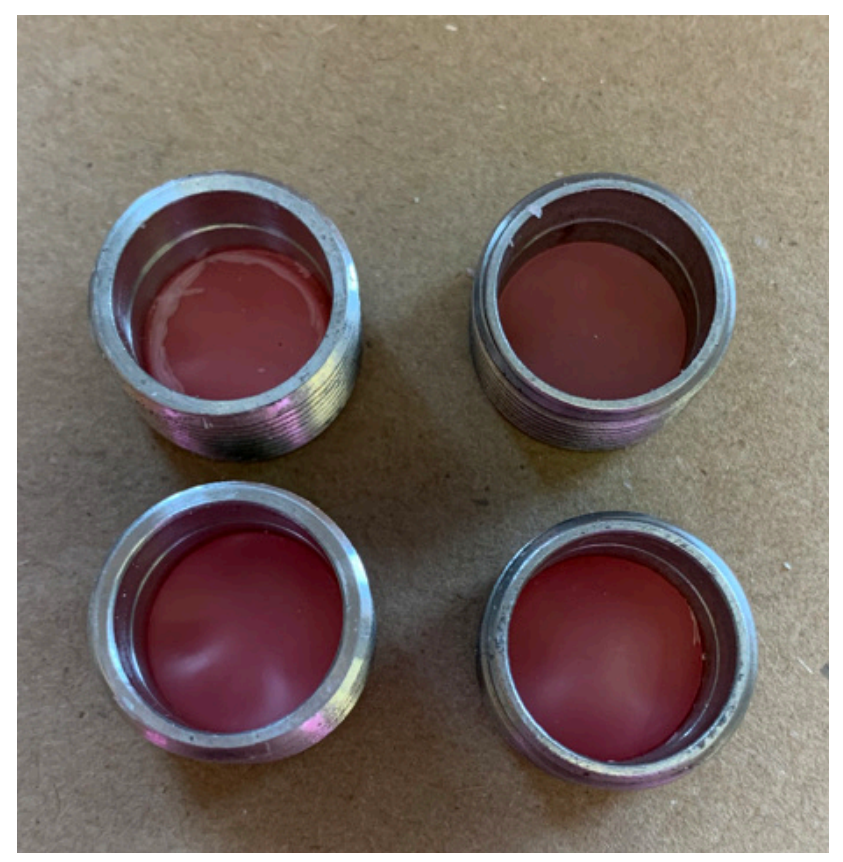

Fig 1. Stainless steel pots prepped with wax base

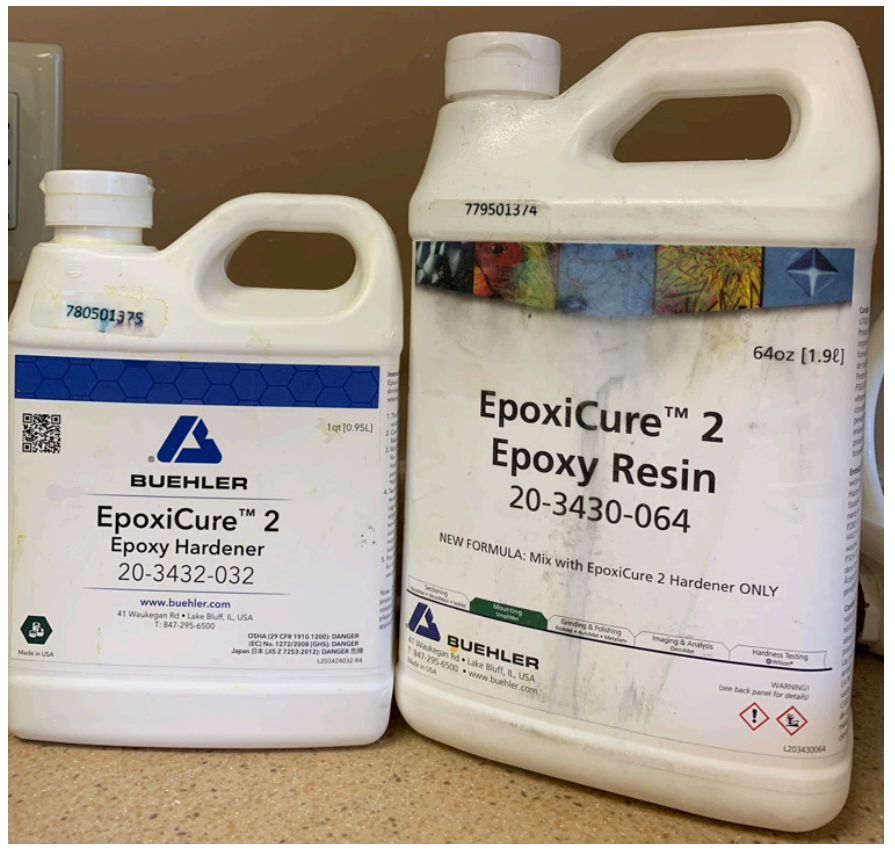

Fig 2. Epoxy Resin components 


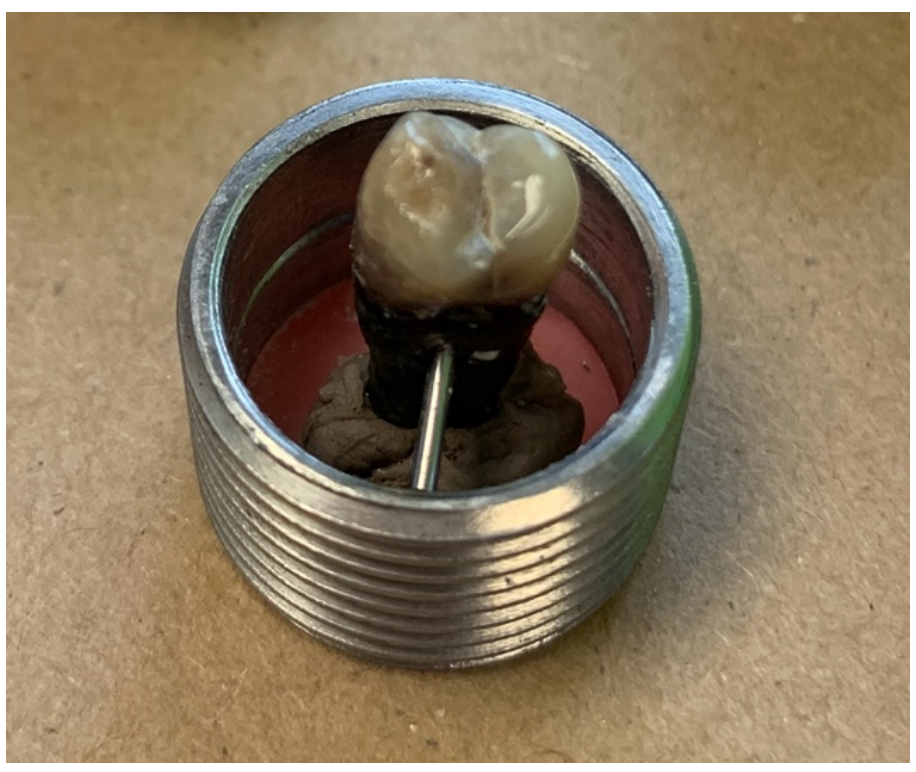

Fig 3. Premolar potted in stainless steel ring prior to testing

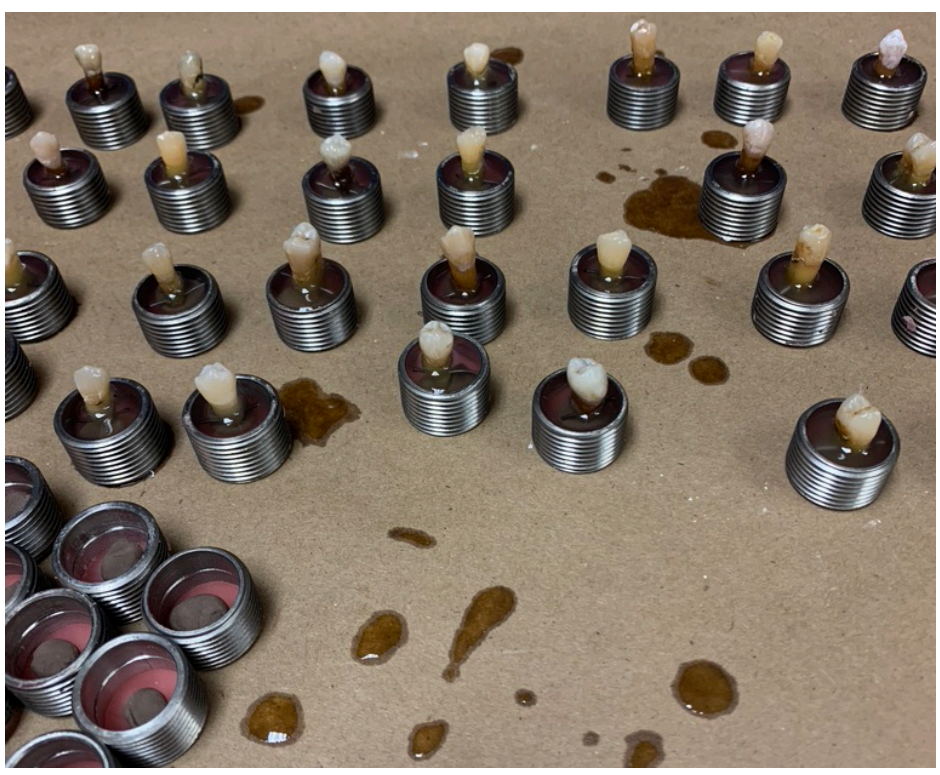

Fig 4. Potted premolars after adding epoxy resin

\section{BONDING PROCEDURES}

\section{Group 1}

1. Prophy teeth with non-fluoride oil-free pumice

2. Air dry thoroughly using oil and moisture-free air source

3. Apply etching agent with applicator (37\% phosphoric acid)

4. Allow 30 seconds for etching, rinse tooth for 5 seconds

5. Dry tooth thoroughly, area should appear frosty white

6. Apply thin coat of Assure ${ }^{\circledR}$ Plus All Surface Bonding Resin to tooth

7. Air dry teeth for 5 seconds to eliminate excess solvent

8. Apply Transbond XT Adhesive to Master Series ${ }^{\circledR}$ metal twin low-profile bracket, then bond bracket to tooth, removing excess adhesive around edges of the bracket

9. Light cure each side of bracket for 3 seconds, for a total of 12 seconds 
Group 2

1. Prophy teeth with non-fluoride oil-free pumice

2. Air dry thoroughly using oil and moisture-free air source

3. Apply etching agent with applicator (37\% phosphoric acid)

4. Allow 30 seconds for etching, rinse tooth for 5 seconds

5. Dry tooth thoroughly, area should appear frosty white

6. Apply thin coat of Assure ${ }^{\circledR}$ Plus All Surface Bonding Resin to tooth

7. Air dry the teeth for 5 seconds to eliminate excess solvent

10. Apply BracePaste ${ }^{\circledR}$ adhesive to Master Series ${ }^{\circledR}$ metal twin low-profile bracket, then bond bracket to tooth, removing excess adhesive around edges of the bracket.

8. Light cure each side of bracket for 3 seconds, total of 12 seconds

\section{THERMOCYCLING}

Samples were placed in an Lindberg/Blue thermocycling machine (Thermo Electron

Corporation, Asheville, NC) for 24 hours. The samples sat in a cold-water bath, $5^{\circ} \mathrm{C}$, for 1

minute, with a 10 second transfer time into a hot water bath maintained at $55^{\circ} \mathrm{C}$, for 1 minute. This cycle was programmed to repeat itself for a total of 24 hours, totaling 627 cycles. 


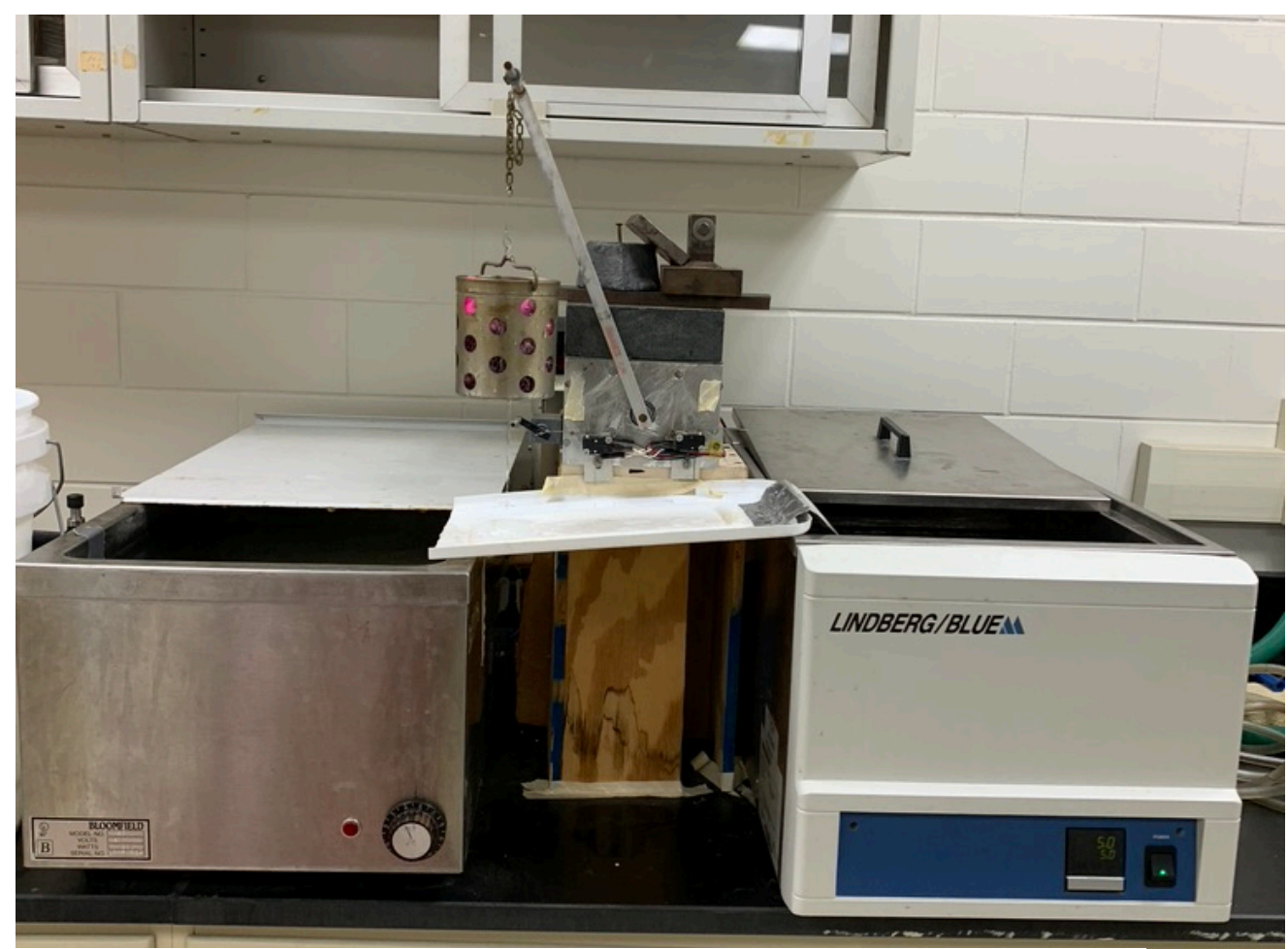

Fig 5. Thermocycler bath loaded with test samples

\section{BOND STRENGTH TESTING}

Debonding forces were determined using an Instron testing machine (Instron Corp., Canton, MA) with a crosshead speed of $1 \mathrm{~mm} /$ minute. The stainless-steel rings were mounted on an adjustable base jig to ensure that the applied force was set up parallel to the long axis of the tooth. The thumb of a disposable glove was cut out and placed over the tooth to catch brackets as they debonded from the tooth. The shearing force was applied at the bracket-tooth interface with an .018 gauge stainless steel wire engaging underneath the gingival wings of the bracket. The force required to debond the bracket was then recorded in Newtons, then converted to megapascals (MPa) by dividing the force in Newtons by the area of the bracket base. Teeth that have catastrophic fracture or were pulled out of the potting epoxy during the debonding process resin were noted and excluded from the results. The debonding procedure was performed in water to simulate and oral environment and prevent excessive dehydration of tooth structure. 


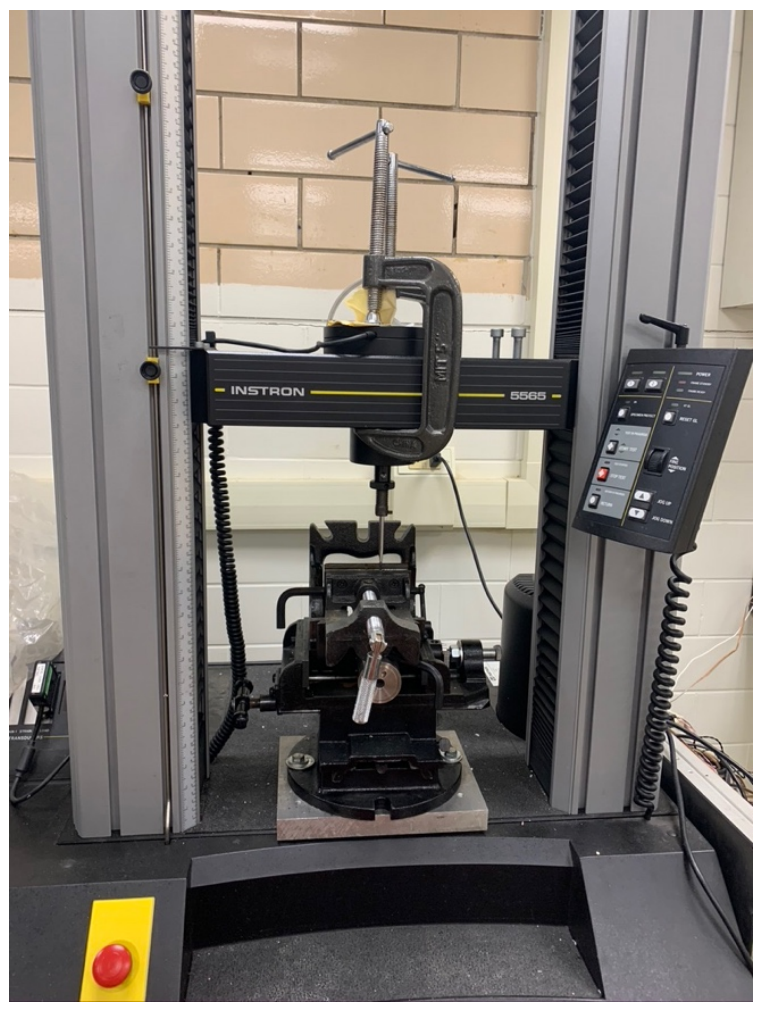

Fig 6. Instron Universal Testing Machine

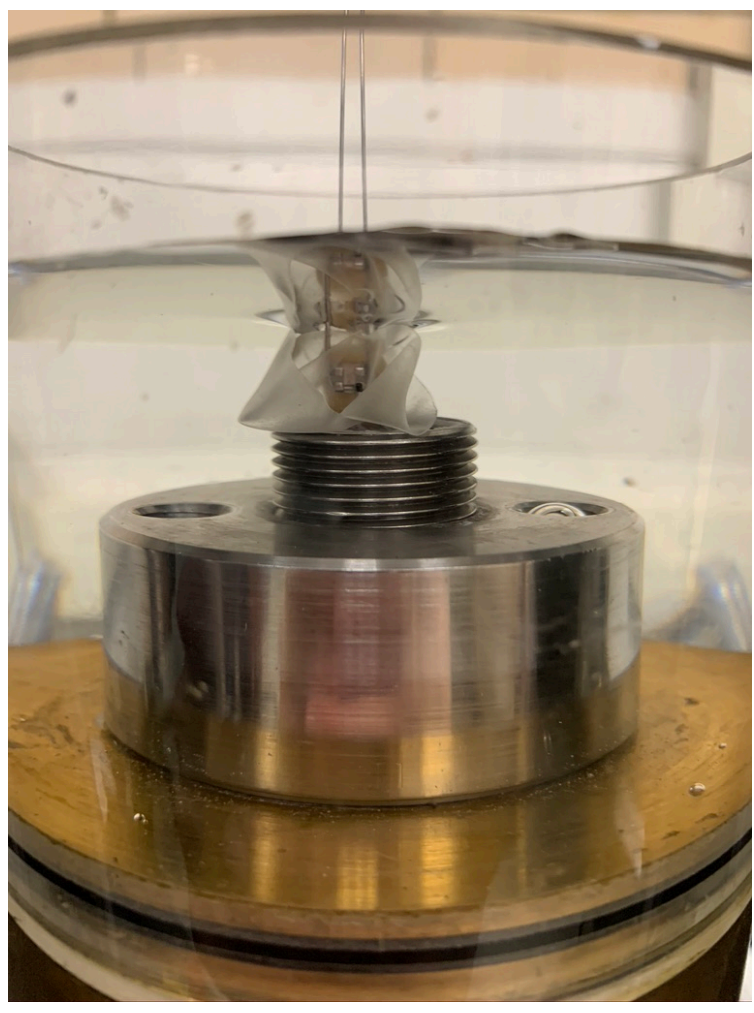

Fig 7. Sample ready for testing in Instron

\section{ADHESIVE REMNANT INDEX MICROSCOPY}

Following debonding, the debonded buccal tooth surfaces were examined with an optical microscope (Gaertner Scientific Corporation, Chicago, Il) at 10x magnification to determine if the failure was at the adhesive interface, tooth-adhesive interface, or bracket-adhesive interface. Evaluation and scoring of the adhesive remnant were carried out by two evaluators, S.B. and E.K., who were calibrated to each other. Evaluation was carried out under 10x magnification. The ARI evaluation used was the conventional 4-point scale (Table 1). A modified ARI scoring system was also used to depict a more detailed failure interface with regard to the bracket instead of tooth (Table 2). 


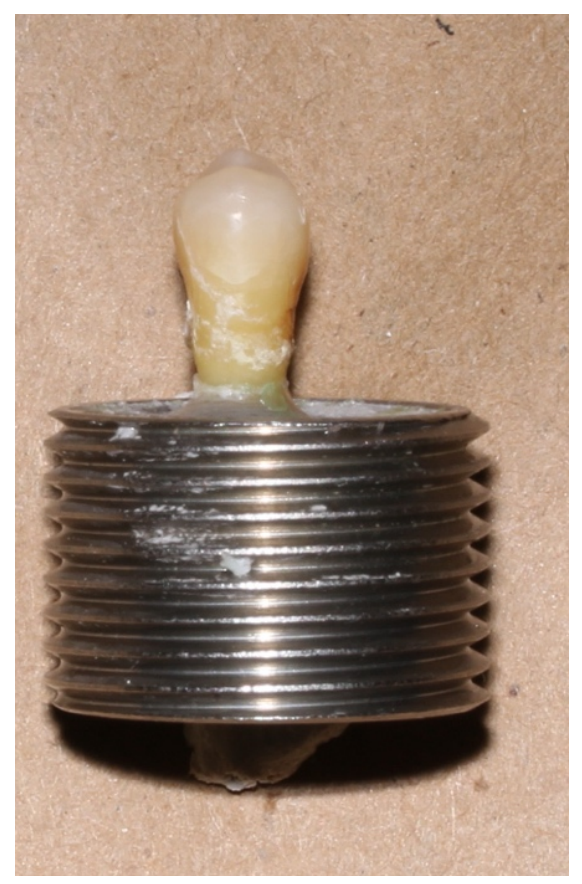

Fig 8A. Artun ARI score 0

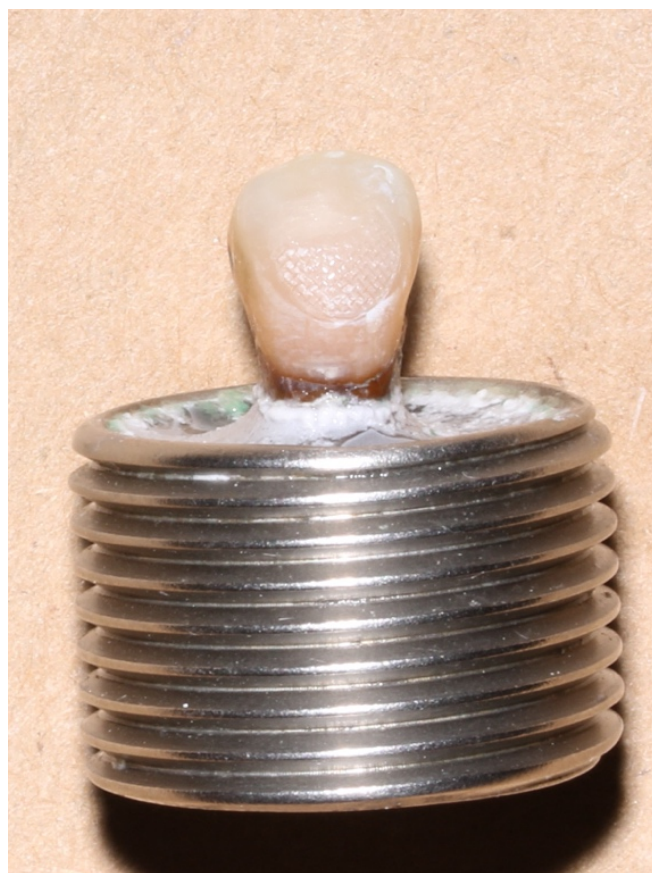

Fig 8C. Artun ARI score 2

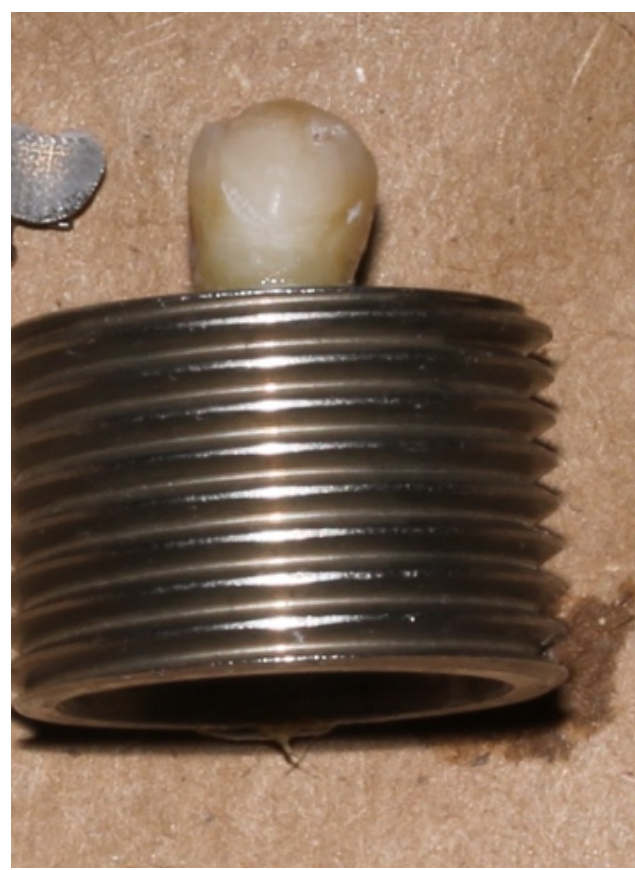

Fig 8B. Artun ARI score 1

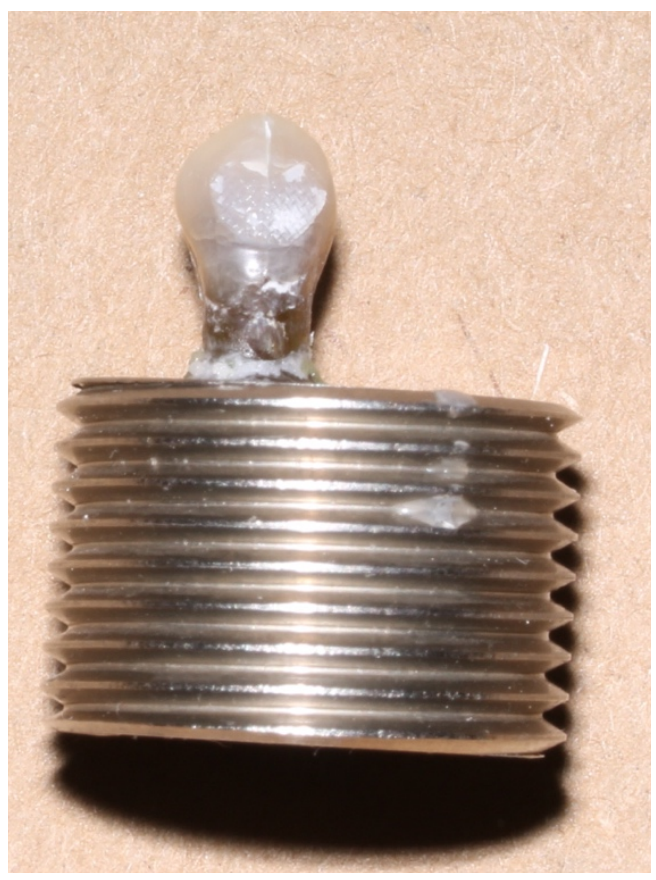

Fig 8D. Artun ARI score 3 


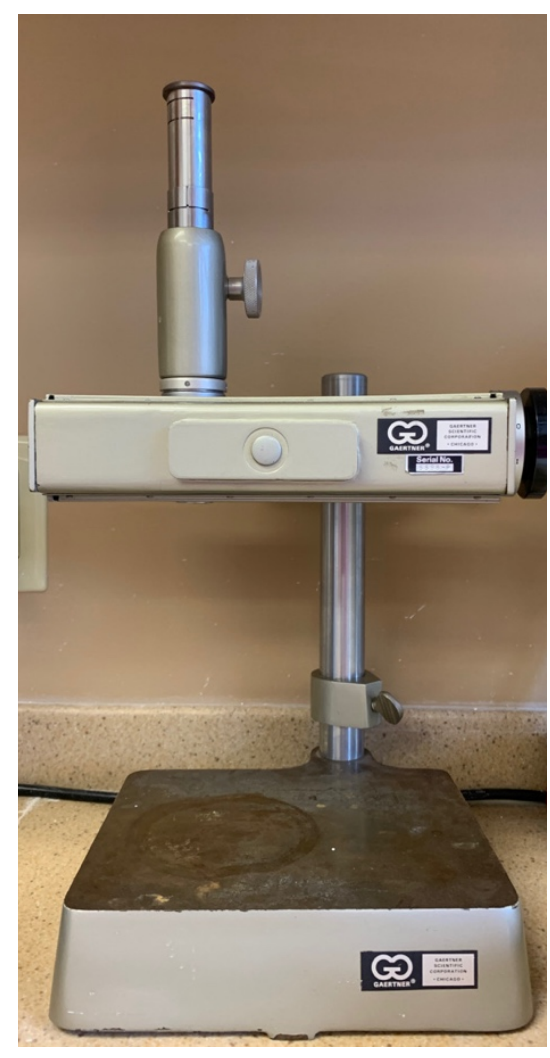

Fig 9. Optical Microscope utilized for ARI scoring

\section{VISUAL INDEX ANALYSIS}

Following ARI analysis, teeth with an Artun score of 1 or 2 were finished and polished so that a visual index analysis could be completed. A carbide finishing bur \#7901 was used with naked eye visualization to remove all adhesive remnants from the teeth. Teeth bonded with Transbond XT were finished under ambient room light, while teeth bonded with BracePaste were finished under ambient room light plus UV light (LUMAND®, China) visualization (Figure 10). After finishing, teeth were polished with a non-fluoridated prophy paste. 

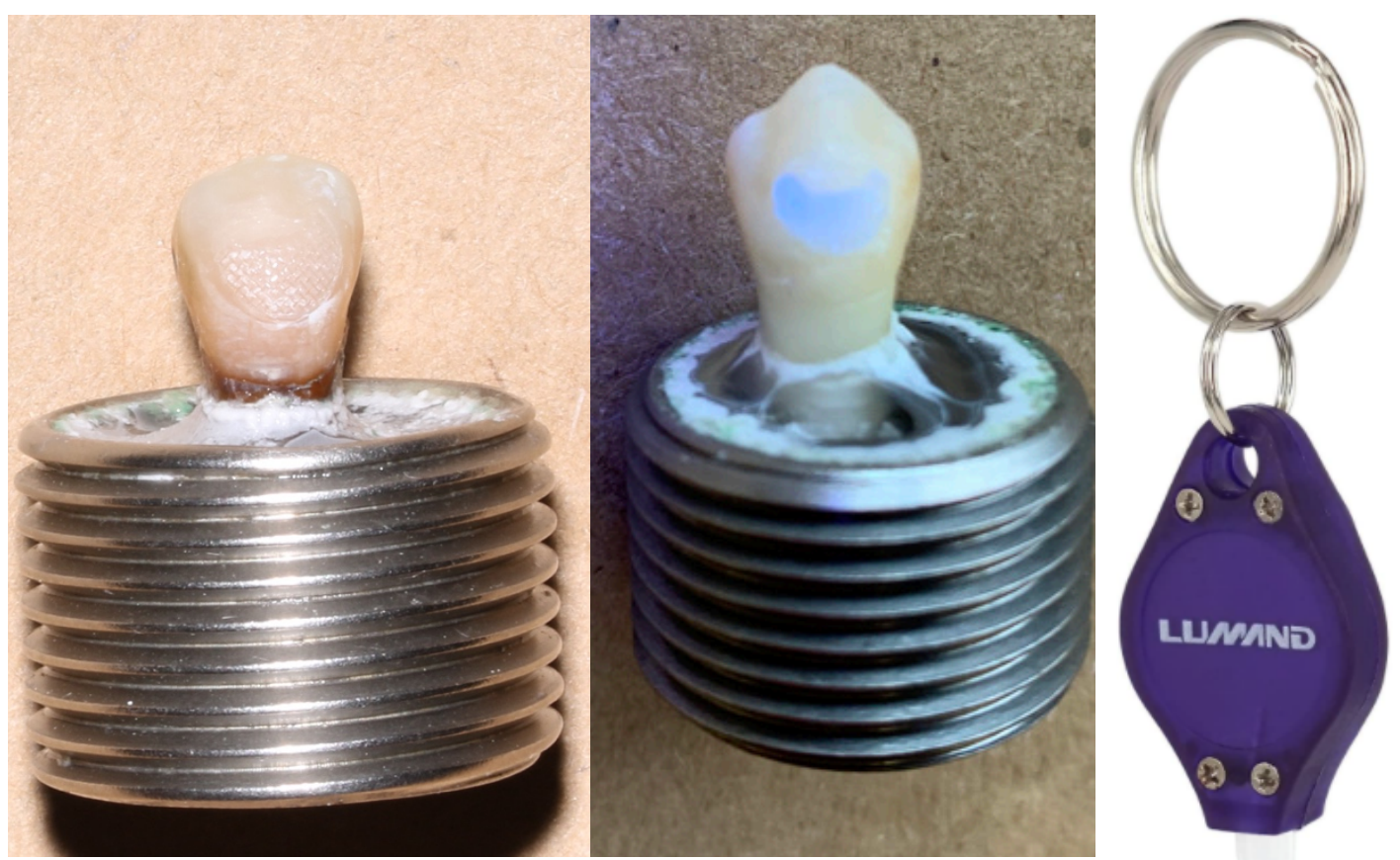

Fig 10. Left: Transbond tooth visualized under ambient light, Middle: BracePaste tooth visualized under UV light, Right: UV light keychain

Remnants on the BracePaste teeth could be easily visualized with UV light and they were removed until none were visualiazed with the UV light. Then, the teeth were scored utilizing a 4-point scoring system developed by Kaneshima et al, with scores A-D (figure 11). ${ }^{31}$ This scoring system allows us to see if UV light as an aid in AR removal leads to significantly different enamel defects in teeth as compared to the conventional ambient light method. "A" indicates absence of removal marks, "B" indicates presence of soft removal marks, "C" indicates presence of more evident removal marks, and " $\mathrm{D}$ " indicates presence of adhesive remnants, as adopted from Kaneshima's study ${ }^{31}$. 

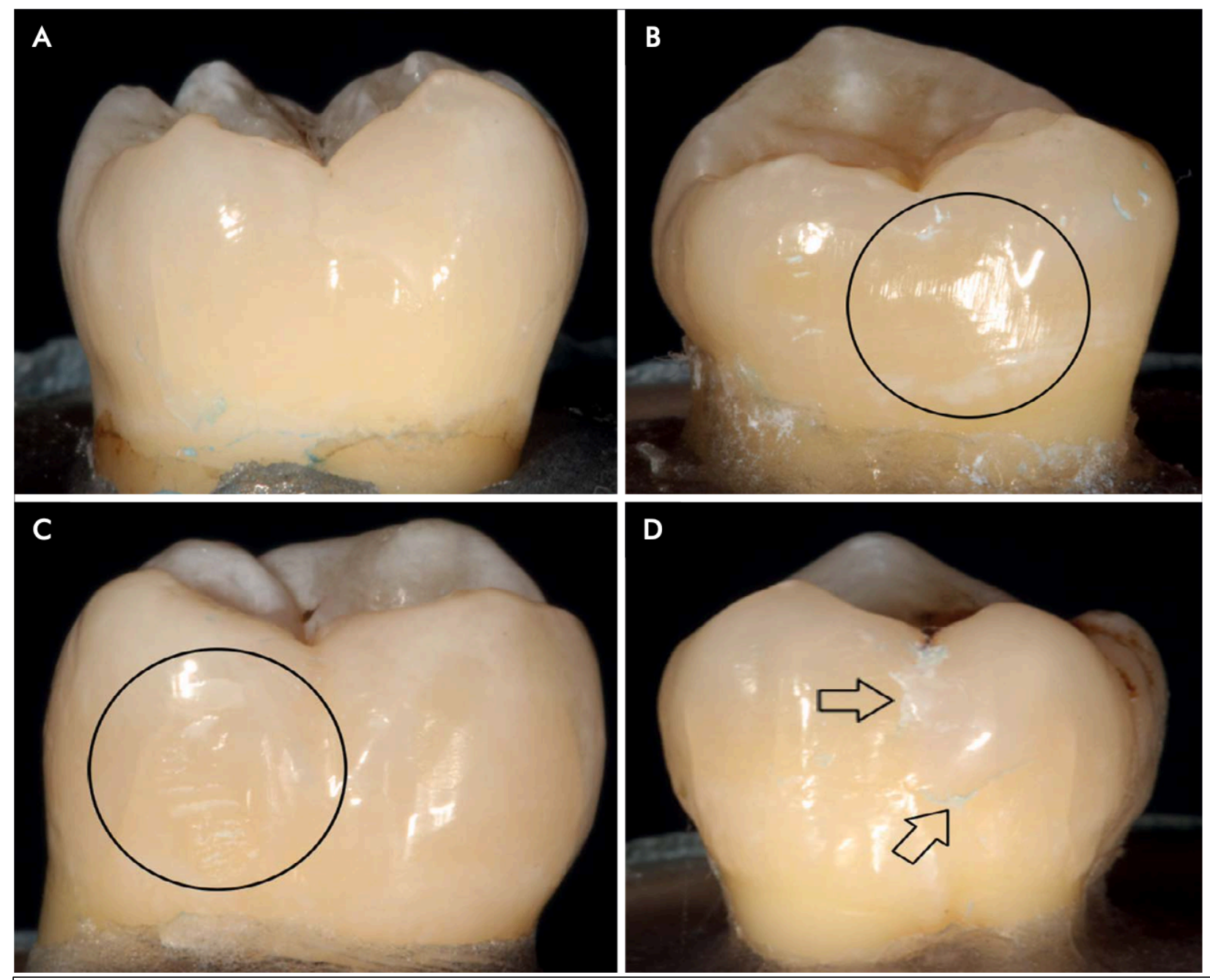

Fig 11. Visual index scores A-D ${ }^{31}$ : A) Intact enamel with no visible enamel removal marks; B) Enamel with soft removal marks, such as scratches; C) Enamel with more pronounced removal marks such as divets and flattened surfaces; D) Dental enamel with presence of adhesive remnants after removal

\section{STATISTICAL ANALYSIS}

SAS (version 9.4, 2013, SAS Institute Inc. Cary, NC) was used to conduct the statistical analysis for the data. We utilized two independent sample t-tests to compare the mean difference in SBS between the Transbond XT and BracePaste groups. Exact Mantel-Haenszel chi-square analysis was conducted to assess the association between ARI scores and the adhesive group. We considered statistical significance for all tests with a two-sided $p$-value of $\leq 0.05$. 


\section{CHAPTER 4: RESULTS}

\section{BOND STRENGTH}

The mean SBS of the two groups were calculated based on an estimated bracket base area of $8.2 \mathrm{~mm}^{2}$. Transbond XT and BracePaste SBS is represented in the table below.

\begin{tabular}{|l|l|l|l|l|l|}
\hline Groups & N & $\begin{array}{l}\text { Mean SBS } \\
(\mathbf{M P a})\end{array}$ & SD & Minimum & Maximum \\
\cline { 4 - 6 } & 16.8 & 7.2 & 4.2 & 32.7 \\
(control) & 33 & & & & \\
\hline BracePaste & 39 & 14.9 & 6.4 & 2.29 & 27.43 \\
\hline
\end{tabular}

Table 3. Comparison of mean shear bond strength (SBS) between groups

The Transbond XT group had a slightly higher mean SBS than the BracePaste group. However, there was no statistically significant difference in the mean SBS between them $(\mathrm{t}(70)=1.2$, $\mathrm{p}=0.23$ ), with there being only a $1.8 \mathrm{MPa}$ difference between the groups.

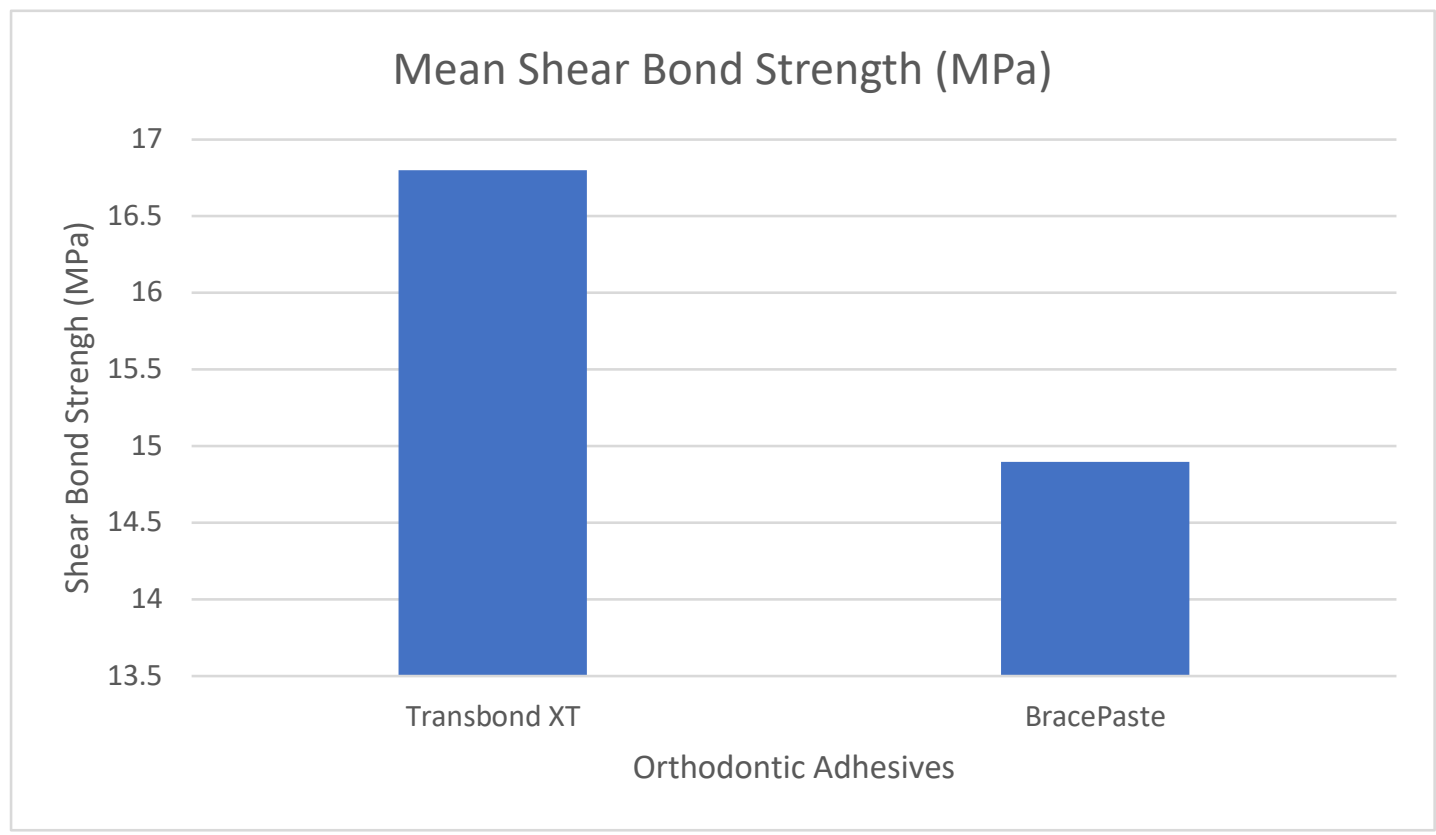

Fig 12. Bar graph comparing mean SBS between adhesives 


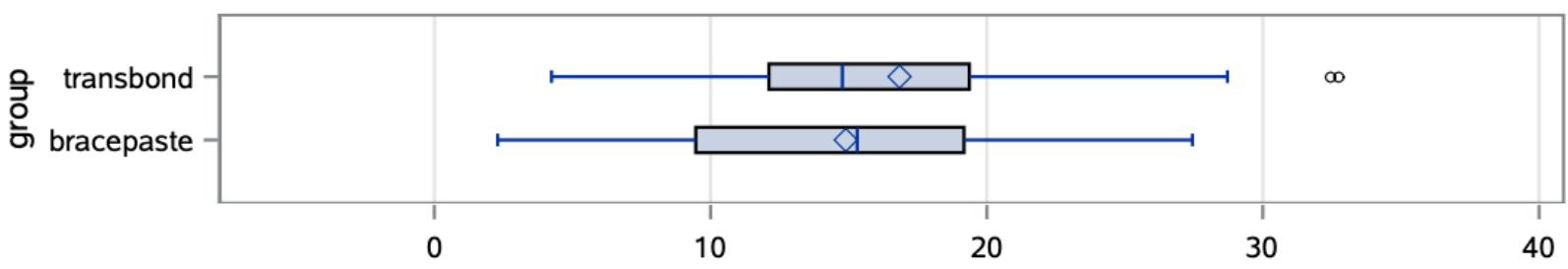

Fig 13. Boxplot of SBS for the two groups

\section{ADHESIVE REMNANT INDEX (ARI)}

In regard to the 6-point ARI scoring system $(0,1,2,3,4,5)$ used for this study, Cohen's Kappa coefficient was calculated for assessing the degree of agreement between the two sets of scores measured by the two raters, S.B. and E.K. The Kappa coefficient (Kappa $=0.68,95 \%$ CI [0.55-0.80]) showed good agreement between the two sets of ARI scores. In regard to the 4-point ARI scoring system $(0,1,2,3)$ that was used for this study, Cohen's Kappa coefficient was calculated for assessing the degree of agreement between the two sets of scores measured by the two raters. The Kappa coefficient (Kappa=0.25, 95 CL [0.07-0.42]) showed of fair agreement between the two sets of ARI scores. The results of exact Mantel-Haenszel chi-square analysis showed no significant difference in ARI scores (6 point ARI scoring system) between the two groups $\left(\chi^{2} \mathrm{MH}(1)=0.25, \mathrm{p}=0.62\right)$. The results of exact Mantel-Haenszel chi-square analysis also showed no significant difference in ARI scores (4 point ARI scoring system) between the two adhesive groups $\left(\chi^{2}{ }_{\mathrm{MH}}(1)=0.85, \mathrm{p}=0.36\right)$. 


\begin{tabular}{|l|l|l|l|}
\hline $\begin{array}{l}\text { ARI SCORE (6- } \\
\text { point) }\end{array}$ & N & Mean SBS (MPa) & SD \\
\hline 0 & 2 & 9.3963415 & 8.3559326 \\
\hline 1 & 23 & 15.4369035 & 7.1096493 \\
\hline 2 & 12 & 19.2652439 & 6.8852711 \\
\hline 3 & 8 & 17.3338415 & 6.4906465 \\
\hline 4 & 18 & 15.6497290 & 5.1301291 \\
\hline 5 & 8 & 12.7484756 & 8.0704648 \\
\hline
\end{tabular}

Table 4 Comparison of mean shear bond strength and ARI (6-point scale) score

\begin{tabular}{|l|l|l|l|}
\hline $\begin{array}{l}\text { ARI SCORE (4- } \\
\text { point) }\end{array}$ & N & Mean SBS (MPa) & SD \\
\hline 0 & 9 & 13.1585366 & 7.6488039 \\
\hline 1 & 18 & 16.1795393 & 6.2609694 \\
\hline 2 & 28 & 16.6437282 & 6.5798987 \\
\hline 3 & 2 & 9.3780488 & 8.3300628 \\
\hline
\end{tabular}

Table 5 Comparison of mean shear bond strength and ARI (4-point scale) score

When comparing ARI to SBS within a group, within the 6-point ARI system, there was no significant difference in mean SBS between the 6 values $(\mathrm{f}=1.44, \mathrm{p}=0.22)$. Similarly, there was no significant difference in mean SBS between the 4 ARI values in the 4-point system $(\mathrm{f}=1.24$, $\mathrm{p}=0.31$ ). Average ARI scores of each group were calculated and are represented in Table 6 below. 


\begin{tabular}{|l|l|l|}
\hline \multicolumn{2}{|c|}{ Average ARI scores for BracePaste and Transbond XT } \\
\hline \multicolumn{1}{|c|}{ Group } & \multicolumn{1}{|c|}{ ARI (4-point scale) } & ARI (6-point scale) \\
\hline BracePaste & 1.5 & 2.5 \\
\hline Transbond XT & 1.2 & 2.7 \\
\hline
\end{tabular}

Table 6. Average ARI scores for BracePaste and Transbond XT

A distribution of ARI scores by percentages was also tabulated and are shown in Tables 7A-B below.

\begin{tabular}{|l|l|l|}
\hline Group & BracePaste & Transbond XT \\
\hline ARI 0 & $5.0 \%$ & $0 \%$ \\
\hline ARI 1 & $25.00 \%$ & $43.75 \%$ \\
\hline ARI 2 & $22.50 \%$ & $9.38 \%$ \\
\hline ARI 3 & $17.5 \%$ & $3.13 \%$ \\
\hline ARI 4 & $27.5 \%$ & $21.88 \%$ \\
\hline ARI 5 & $2.5 \%$ & $21.88 \%$ \\
\hline
\end{tabular}

Table 7A. Percentage of each 6-point (modified) ARI score represented among groups

\begin{tabular}{|l|l|l|l|l|}
\hline \multicolumn{5}{|c|}{ Percentage Representation of ARI scores (4-point scale) in groups } \\
\hline Group & ARI 0 & ARI 1 & ARI 2 & ARI 3 \\
\hline BracePaste & $3.03 \%$ & $45.45 \%$ & $45.45 \%$ & $6.06 \%$ \\
\hline Transbond XT & $32.0 \%$ & $12.00 \%$ & $56.00 \%$ & $0 \%$ \\
\hline
\end{tabular}

Table 7B. Percentage of each 4-point ARI score represented among groups 


\section{VISUAL ANALYSIS}

The results obtained by direct visual analysis, after AR removal and polishing (Table 8) of teeth scored a 1 or 2 using the 4-point Artun scoring system, showed no significant difference $\left(\chi^{2} \mathrm{MH}(1)=0.21, \mathrm{p}=0.71\right)$ between the two different adhesive systems; this is similar to results of other previous research analyzing AR removal with and without UV light. ${ }^{31}$ It may be noted (see Appendix) that one tooth from each group, Transbond \#35 and BracePaste \#42, still showed adhesive remnants (score "D") after AR removal.

\begin{tabular}{|l|l|l|l|l|}
\hline \multicolumn{2}{|c|}{ VISUAL ANALYSIS OF ENAMEL MARKS AFTER AR REMOVAL } \\
\hline GROUP & $\begin{array}{l}\text { A } \\
\text { Absence of } \\
\text { marks }\end{array}$ & $\begin{array}{l}\text { B } \\
\text { Soft marks }\end{array}$ & $\begin{array}{l}\text { C } \\
\text { Evident } \\
\text { marks, } \\
\text { divets }\end{array}$ & TOTAL \\
\hline TRANSBOND XT & 1 & 11 & 9 & 21 \\
& 1.92 & 21.15 & 17.31 & 40.38 \\
& 4.76 & 52.38 & 42.86 & \\
\hline BRACEPASTE & 20.00 & 52.38 & 34.62 & \\
& 4 & 10.0 & 17 & 31 \\
& 7.69 & 19.23 & 32.69 & 59.62 \\
& 12.90 & 32.26 & 54.84 & \\
& 80.00 & 47.62 & 65.38 & \\
\hline TOTAL & 5 & & 21 & 52 \\
& 9.62 & 40.38 & 50.0 & 100.0 \\
\hline
\end{tabular}

Frequency $(\mathrm{N})$

Percent \%

Row \%

Column \%

Table 8. Direct visual analysis after the removal of adhesive remnants (AR) and after polishing, considering the different adhesives tested, $\left.\chi^{2}{ }_{\mathrm{MH}}(1)=0.21, \mathrm{p}=0.71\right)$. 


\section{NULL HYPOTHESIS}

1. There is no significant difference between the SBS of "BracePaste" and "Transbond XT": ACCEPTED

2. There is no significant difference in mean SBS between different degrees of ARI: ACCEPTED

3. There is no significant difference between the visual index analysis values of "BracePaste" and "Transbond XT": ACCEPTED 


\section{CHAPTER 5: DISCUSSION}

This study measured the SBS of two different orthodontic adhesive resins (BracePaste and Transbond XT) with the use of stainless-steel metal Master Series ${ }^{\circledR}$ twin low-profile brackets. Low-profile brackets were chosen as they are desirable for patients for a couple reasons. First of all, the more compact profile of them makes them less noticeable, thus more esthetic. This is a much-desired feature for patients in orthodontic treatment. Additionally, the less bulky characteristic of this type of bracket as compared to the conventional metal bracket is increased patient comfort. ${ }^{33}$ The force of bracket debonding was represented using Newtons (N). Shear bond strength, represented here in Megapascal (MPa) units, was calculated by taking the $\mathrm{N}$ and dividing that by the area of the orthodontic bracket base. American Orthodontics was unable to release proprietary bracket dimension information, so the best estimated bracket dimension in this study was calculated from our own measurements. It was determined that the maxillary right first premolar metal bracket (used on all teeth in the study) had a total surface area of $8.2 \mathrm{~mm}^{15}$. Using this information to calculate mean bond strength, it was determined that the mean SBS of the BracePaste adhesive group was not significantly different than that of the established gold standard Transbond XT group. The SBS of Transbond XT, the control, was found to be 16.8MPa. This supports previous research, which shows Transbond XT having a SBS of 10.32MPa-15.5 MPa. ${ }^{34,35}$ The novel adhesive BracePaste showed a similar result to Transbond XT, with this fluorescent adhesive having a mean SBS of 14.9MPa. Many studies have developed suggested SBS values for clinical situations, with values ranging from 5.9MPa to 10.0MPa being sufficient to prevent unwanted bracket debond. ${ }^{13,36-39}$ With BracePaste demonstrating a mean SBS of $14.8 \mathrm{MPa}$ in this study, it can be reasoned that this new adhesive shows a bond strength value that is adequate for clinical situations. It is important to note that 
Katona found that it is impossible to apply a pure shear load to a bracket due to an unavoidable inherent bending moment. ${ }^{40}$ Thus, SBS is truly more of a "shear-peel strength", but many studies use the term shear bond strength when, in fact, testing shear-peel bond strength. ${ }^{40}$ While an orthodontic adhesive must show bond strength appropriate for withstanding masticatory forces, too high of a bond strength is undesirable, so manufacturers must find an appropriate balance when developing their adhesive. Adhesion forces reaching 40MPa-50MPa are so strong to the extent that there is risk for enamel damage upon debond, so values this high should be avoided. ${ }^{41}$ Thus, the ideal orthodontic adhesive should have SBS values in the range of $6 \mathrm{MPa}-40 \mathrm{MPa}^{42}$ With Transbond XT seen as the gold standard in orthodontic bonding, our results also confirm that this adhesive is in the appropriate range to be used for bonding brackets to tooth. Additionally, our results demonstrated that BracePaste is a clinically acceptable adhesive to use, with a SBS value that is within the recommended range for clinical application.

ARI is a useful tool to measure the adhesion failure for orthodontic brackets, especially when studying SBS. Two different ARI scoring systems were utilized: a 4-point system $(0,1,2,3)$ developed by $\operatorname{Artun}^{28}$ and a 6-point system $(0,1,2,3,4,5)$ developed by Attar ${ }^{29}$. Artun's system viewed leftover adhesive in relation to the tooth surface, while Attar measured the remnants in regard to the bracket surface. Using these systems, a correlation can be derived between amount of adhesive left on the tooth/bracket and where the failure occurred. In orthodontics, an adequate bond, which fails at the enamel-adhesive interface, would be desirable as this type of failure would allow for less residual resin on tooth surface and subsequent polishing to become easier. ${ }^{20}$ A low score, such as 0 or 1 , scored using the 6-point system would indicate that either no, or very little adhesive was left on the debonded bracket. This would then infer that adhesive failure 
occurred between the bracket-adhesive interface; thus, a higher proportion of residual adhesive would remain on the tooth enamel.

A large amount of adhesive remaining on the enamel, then, would score high on the 4point system. With most of the adhesive remaining on the enamel and little to none present on the bracket in this scenario, it is implied that there was a strong bond between the adhesive and tooth. On the other hand, in the 6-point system, a high score such as 5 or 6 would suggest that the adhesive failure occurred at the enamel-adhesive interface, as much adhesive remained on the bracket. Thus, this description would correspond to a low score using the Artun ARI scale.

With most of the adhesive being on the bracket and little to none present on the enamel, it is implied that there was a weak bond of adhesive to enamel. From a clinical perspective, a low Artun ARI score or a high Attar ARI score is desirable because less residual adhesive remaining on enamel after debond means an easier, and potentially quicker finishing and polishing. However, a low Artun ARI score may mean that the bond between the adhesive and tooth was too weak and not enough to withstand the forces of mastication. Thus, a low Artun ARI score combined with a clinically acceptable SBS value would be characteristics of an ideal adhesive. A study by Linn showed that brackets direct bonded with Transbond XT mainly scored "1" on the 4-point ARI scale, which suggests that this adhesive is ideal for orthodontic bonding. ${ }^{43}$ However, previous studies by Sharma and D'Atillio reported that Transbond XT bonded to extracted premolars showed an ARI score of "3" being most prevalent, with $40 \%$ of samples having this score. ${ }^{20,44}$ In comparison, the current study showed a $56 \%$ rating of "2" (Table 7A) for Transbond XT, suggesting that even though not all Transbond remained on the tooth surface, but a larger proportion was present there; thus, a cohesive failure was present. This is in agreement with a study performed by Rix, which showed Transbond XT displaying its highest distribution 
of scores, 30\%, as ARI “2”. ${ }^{45}$ Conversely, Bracepaste was split equally among distribution of ARI scores between "1" and "2" (Table 7A), suggesting a trend for less adhesive to remain on the tooth in comparison to Transbond XT, but still with cohesive failures.

In relation to enamel surface quality after removal of AR in either group, results were obtained showing that there was no significant difference in damage to enamel surface using either UV light with BracePaste to remove remnants or ambient room light with Transbond XT to remove remnants. This was verified with direct visual analysis (Table 8). Studies by Ribiero and Lai ${ }^{46-47}$ showed that there was a smaller amount of adhesive remaining after remnant removal procedures for teeth that had been finished using UV light as opposed to just operatory light. The current study found adhesive remnants on one tooth from each group. Perhaps a larger sample size would have provided different results. 


\section{CHAPTER 6: SUMMARY AND CONCLUSIONS}

\section{SUMMARY}

The purpose of this study was to compare the in vitro shear bond strength between the “gold standard" adhesive, Transbond XT, to a novel UV fluorescent adhesive, BracePaste. Transbond XT had a slightly greater mean SBS value, 16.8MPa, than BracePaste, which had a mean shear SBS value of $14.9 \mathrm{MPa}$. This small difference was not statistically significant, so both adhesives perform equally under shearing forces and are considered to be clinically acceptable for use in orthodontic bonding protocols.

In regard to differences in ARI scores between the two adhesives, there was no significant differences in ARI scores, whether using the 4-point ARI scoring system or the 6point system. Furthermore, within the 6-point ARI system, there was no significant difference in mean SBS between the 6 values. Similarly, there was no significant difference in mean SBS between the 4 ARI values in the 4-point system.

The quality of enamel after AR removal, finishing, and polishing, was assessed using a visual index grading scale. This scale measured the severity of enamel scratches subsequent to these procedures and also measured if any AR still remained afterward. Statistical analysis showed that there was no significant difference between the two groups for the visual index values. None of the finishing and polishing procedures cause significantly different resulting enamel surface either with the aid of ambient light or UV light. 


\section{CONCLUSIONS}

1. From the findings of this study, it was concluded that there was no significant difference between Transbond XT and BracePaste in SBS values.

2. Transbond XT and BracePaste were identified to have mean shear bond strenghts above the minimal clinical accepted values.

3. After AR removal, none of the finishing and polishing procedures caused significantly different resulting enamel surface defects either with the use of ambient light or UV light 


\section{RECOMMENDATIONS}

Future in vitro studies could further investigate the efficacy of BracePaste and similar new adhesives by including a time analysis. Some debonding methods that excel in preservation of enamel tend to be more involved, both in clinical time needed and higher cost. ${ }^{48}$ So, a comparison of adhesive remnant removal time between a UV light system and standard ambient light would provide valuable insight into the amount of time saved or lost by introducing a UV light system for AR removal. Schott developed a technique whereby the UV light source is introduced from the dental handpiece, so this may prove a useful comparison to AR removal using ambient room light. ${ }^{8}$ Additionally, analysis of finished and polished teeth with scanning electron microscopy (SEM) could supplement the visual analysis index to make sure both are in agreement.

While in vitro study gives a relatively controlled environment for testing, future in vivo studies are warranted to assess the efficacy of BracePaste in the mouth, which takes into account factors such as salivary $\mathrm{pH}$ and mastication. In vivo studies normally produce lower SBS readings, likely due to salivary $\mathrm{pH}$ and mastication, than in vitro studies, so while BracePaste has clinically acceptable SBS rates in vitro, it is critical to see if this holds true in clinical studies. ${ }^{49}$ In vitro studies need to be conducted with fully healthy intact enamel teeth. In many instances, teeth fractured, roots separated, or there were previous restorations that affected the placement of the bracket or integrity of the tooth during this study, so these factors need to be taken into account. Furthermore, future studies may investigate the effects of newer adhesives as well as different orthodontic brackets and base meshes. In vitro studies are useful for obtaining preliminary data, such as SBS, on new products on the market before time and effort is spent during more fastidious in vivo testing. There is a plethora of orthodontic brackets, adhesives, and 
mesh bases available, all of which will have an effect on SBS, ARI, and enamel quality after AR removal. Continuing to study these new products can aid in determining the most efficient, effective, and safe protocol for bonding and removing AR after orthodontic debond.

For this study, no comparison of time necessary to remove the adhesive remnants from the enamel surface after bonding was completed. It took time to illuminate, finish, and polish the surfaces with interrupted stops to put the keychain light down. Using a handpiece than can deliver UV light, such as was done in a study by Kaneshime ${ }^{31}$, could be useful in determining if utilization of UV light can result in a quicker time in finishing and polishing. 


\section{REFERENCES}

1. Jassem HA, Retief DH, Jamison HC. Tensile and shear strengths of bonded and rebonded orthodontic attachments. American journal of orthodontics. 1981;79(6):661-668.

2. Ribeiro AA, Almeida LF, Martins LP, Martins RP. Assessing adhesive remnant removal and enamel damage with ultraviolet light: An in-vitro study. Am J Orthod Dentofacial Orthop. 2017 Feb;151(2):292-296.

3. Murray PG, Millett DT, Cronin M. Bonded molar tubes: a survey of their use by specialist orthodontists. J Orthod. 2012 Jun;39(2):129-35.

4. Ryf S, Flury S, Palaniappan S, Lussi A, van Meerbeek B, Zimmerli B. Enamel loss and adhesive remnants following bracket removal and various clean-up procedures in vitro. Eur $J$ Orthod. 2012 Feb;34(1):25-32.

5. Fitzpatrick DA, Way DC. The effects of wear, acid etching, and bond removal on human enamel. Am J Orthod. 1977 Dec;72(6):671-81.

6. Eminkahyagil N, Arman A, Çetinsahin A, Karabulut E. Effect of resin-removal methods on enamel and shear bond strength of rebonded brackets. Angle Orthod. 2006;76:314-321.

7. Hong YH, Lew KKK. Quantitative and qualitative assessment of enamel surface following five composite removal methods after bracket debonding. Eur J Orthod. 1995;17:121-128.

8. Schott TC, Meller C. A new Fluorescence-aided Identification Technique (FIT) for optimal removal of resin-based bracket bonding remnants after orthodontic debracketing. Quintessence Int. 2018;49(10):809-813.

9. Gange P. The evolution of bonding in orthodontics. American Journal of Orthodontics and Dentofacial Orthopedics. 2015;147(4):S56 - S63.

10. Newman GV. Epoxy adhesives for orthodontics attachments: progress report. $\mathrm{Am} J$ Orthod. 1965;51:901-912.

11. Joseph VP, Rossouw E. The shear bond strengths of stainless steel and ceramic brackets used with chemically and light-activated composite resins. Am J Orthod Dentofacial Orthop. 1990;97:121-5.

12. Mohammed RE, Abass S, Abubakr NH, Mohammed ZM. Comparing orthodontic bond failures of light-cured composite resin with chemical-cured composite resin: A 12-month clinical trial. Am J Orthod Dentofacial Orthop. 2016 Aug;150(2):290-4.

13. Reynolds IR. A review of direct orthodontic bonding. Br J Orthod. 1975;2:171-8 
14. El Mourad AM. Assessment of Bonding Effectiveness of Adhesive Materials to Tooth Structure using Bond Strength Test Methods: A Review of Literature. Open Dent J. 2018;12:664-678.

15. Sha HN, Choi SH, Yu HS, Hwang CJ, Cha JY, Kim KM. Debonding force and shear bond strength of an array of CAD/CAMbased customized orthodontic brackets, placed by indirect bonding- An In Vitro study. PLoS One 2018;13(9):e0202952

16. Gillis I, Redlich M. The effect of different porcelain conditioning techniques on shear bond strength of stainless steel brackets. American Journal of Orthodontics and Dentofacial Orthopedics. 1998;114(4):387-392.

17. Brantley WA, Eliades T. Orthodontic Materials: Scientific and Clinical Aspects. Stuttgart, Thieme: Germany; 2001.

18. Öztürk B, Malkoç S, Koyutürk AE, Çatalbaş B, Özer F. Influence of different tooth types on the bond strength of two orthodontic adhesive systems. European Journal of Orthodontics. 2008;30(4):407-412.

19. Shams S, Abela S, Andiappan M, Hajiheshmati A, Bister D (2020) Shear Bond Strengths of 3 Commonly Used Orthodontic Adhesives. Dentistry 10: 568. doi: 10.35248/2161-

1122.20.10.568

20. Sharma S, Tandon P, Nagar A, Singh GP, Singh A, Chugh VK. A comparison of shear bond strength of orthodontic brackets bonded with four different orthodontic adhesives. J Orthodont Sci. 2014;3:29-33.

21. Gale MS, Darvell BW. Thermal cycling procedures for laboratory testing of dental restorations. J Dent. 1999;27:89- 99.

22. Bishara SE, Ajlouni R, Laffoon JF. Effect of thermocycling on the shear bond strength of a cyanoacrylate orthodontic adhesive. Am J Orthod Dentofacial Orthop. 2003;123:21- 24.

23. Signorelli MD, Kao E, Ngan PW, Gladwin MA. Comparison of bond strength between orthodontic brackets bonded with halogen and plasma arc curing lights: An in-vitro and in-vivo study. Am J Orthod Dentofac Orthop. 2006;129(2):277-282.

24. Mirzakouchaki B, Kimyai S, Hydari M, Shahrbaf S, Mirzakouchaki-Boroujeni P. Effect of self-etching primer/adhesive and conventional bonding on the shear bond strength in metallic and ceramic brackets. Med Oral Patol Oral Cir Bucal. 2012;17(1):164-170.

25. Daub J, Berzins DW, Linn BJ, Bradley TG. Bond strength of direct and indirect bonded brackets after thermocycling. Angle Orthod. 2006 Mar;76(2):295-300. doi: 10.1043/00033219(2006)076[0295:BSODAI]2.0.CO;2. 
26. Komori A, Ishikawa H. Evaluation of resin-modified glass ionomer cement for use as an orthodontic bonding agent. Angle Orthod. 1997;67:183-196.

27. Bishara SE, Khowassah AM, Oesterle LJ. Effect of humidity and temperature changes on orthodontic direct-bonding adhesive systems. J Dent Res. 1975;54:751-757

28. Artun J, Bergland S (1984) Clinical trials with crystal growth conditioning as an alternative to acid-etch enamel pretreatment. Am J Orthod 85(4): 333-340.

29. Attar N, Korkmaz Y, Kilical Y, Saglam-Aydinatay B, Bicer CO. Bond strength of orthodontic brackets bonded to enamel with a self-etching primer after bleaching and desensitizer application. Korean J Orthod. 2010;40:342-348.

30. Cehreli SB, Polat-Ozsoy O, Sar C, Cubukcu HE, Cehreli ZC. A comparative study of qualitative and quantitative methods for the assessment of adhesive remnant after bracket debonding. Eur J Orthod. 2012;34(2):188-192.

31. Kaneshima EN, Berger SB, Fernandes TMF, Navarro MFL, Oltramari PVP. Using UV light for adhesive remnant removal after debonding of orthodontic accessories. Braz Oral Res. 2018 Sep 21;32:e47.

32. Bernstein C. Effect of Shear Bond Strength with Novel APCTM Flash-Free Brackets and Different Bonding Protocol: An In Vitro Study. WVU Master Thesis. 2019.

33. Geron, S. Self-Ligating Brackets in Lingual Orthodontics. Seminars in Orthodontics. 2008;14: 64-72.

34. Shukla C, Singh G, Jain U, Swamy K. Comparison of Mean Shear Bond Strength of Light Cure, Self-Cure Composite Resins, Self-Etching and Moisture-Insensitive Primers: An in vitro Study. J Ind Orthod Soc 2012;46(4):254-257

35. Hellak A, Ebeling J, Schauseil M, Stein S, Roggendorf M, Korbmacher-Steiner H. Shear Bond Strength of Three Orthodontic Bonding Systems on Enamel and Restorative Materials. Biomed Res Int. 2016;2016:6307107. doi:10.1155/2016/6307107

36. Keizer S, Ten Cate JM, Arends J. Direct bonding of orthodontic brackets. Am J Orthod Dentofac Orthop. 1976;69:318-327.

37. Lopez JI. Retentive shear strengths of various bonding attachment bases. Am J Orthod Dentofac Orthop. 1980;77:669-678

38. Buonocore MG. Principles of adhesive retention and adhesive restorative materials. $J$ Am Dent Assoc. 1963;67:382-391

39. Miura F, Nakagawa K, Masuhara E. A new direct bonding system for plastic brackets. $A m J$ Orthod Dentofac Orthop. 1971;59:350-36. 
40. Katona TR. The effects of load location and misalignment on shear/peel testing of direct bonded orthodontic brackets-a finite element model. Am J Orthod Dentofacial Orthop 1994. 106:395-402.

41. Giannini M, Soares CJ, de Carvalho RM. Ultimate tensile strength of tooth structures. Dent Mater. 2004 May;20(4):322-9. doi: 10.1016/S0109-5641(03)00110-6. PMID: 15019445.

42. Scribante A, Contreras-Bulnes R, Montasser MA, Vallittu PK. Orthodontics: Bracket Materials, Adhesives Systems, and Their Bond Strength. Biomed Res Int. 2016;2016:1329814. doi:10.1155/2016/1329814

43. Linn BJ, Berzins DW, Dhuru VB, Bradley TG. A comparison of bond strength between direct- and indirect-bonding methods. Angle Orthod. 2006 Mar;76(2):289-94. doi: 10.1043/00033219(2006)076[0289:ACOBSB]2.0.CO;2. PMID: 16539556.

44. D'Attilio M, Traini T, Di Iorio D, Varvara G, Festa F, Tecco S. Shear bond strength, bond failure, and scanning electron microscopy analysis of a new flowable composite for orthodontic use. Angle Orthod. 2005 May;75(3):410-5. doi: 10.1043/00033219(2005)75[410:SBSBFA]2.0.CO;2. PMID: 15898382.

45. Rix D, Foley TF, Mamandras A. Comparison of bond strength of three adhesives: composite resin, hybrid GIC, and glass-filled GIC. Am J Orthod Dentofacial Orthop. 2001 Jan;119(1):3642. doi: 10.1067/mod.2001.110519. PMID: 11174538.

46. Lai C, Bush PJ, Warunek S, Covell DA Jr, Al-Jewair T. An in vitro comparison of ultraviolet versus white light in the detection of adhesive remnants during orthodontic debonding. Angle Orthod. 2019;89(3):438-445. doi:10.2319/072018-526.1

47. Ribeiro AA, Almeida LF, Martins LP, Martins RP. Assessing adhesive remnant removal and enamel damage with ultraviolet light: an in-vitro study. Am J Orthod Dentofacial Orthop. 2017;151:292-296.

48. Karan S, Kircelli BH, Tasdelen B. Enamel surface roughness after debonding. Angle Orthod. 2010 Nov;80(6):1081-8. https://doi.org/10.2319/012610-55.1

49. Pickett KL, Sadowsky PL, Jacobson A, Lacefield W. Orthodontic in vivo bond strength: comparison with in vitro results. Angle Orthod. 2001 Apr;71(2):141-8. doi: 10.1043/00033219(2001)071<0141:OIVBSC $>2.0$.CO;2. PMID: 11302591. 


\section{W. WestVirginiaUniversity. \\ OFFICE OF HUMAN RESEARCH PROTECTIONS \\ 886 Chestnut Ridge Road Morgantown, WV 26506}

\section{Acknowledgement of Not Human Subjects Research}

To: Chris Martin

From: WVU Office of Research Integrity \& Compliance

Protocol Type: NHSR / Flex

Approval Date: 10/24/2019

Submission Type: Initial

Expiration Date: 10/23/2024

Funding: N/A

WVU Protocol \#: 1910741290

Protocol Title: An In Vitro Comparison of Shear Bond Strength Between Two Orthodontic Light-Curable Adhesive Pastes

The West Virginia University Institutional Review Board has determined that your protocol submission of protocol 1910741290 does not meet the definition of human subjects research, as provided in 45 CFR 46. This determination was based on the following:

- Research means a systematic investigation designed to develop or contribute to generalizable knowledge. Most case reports and most oral histories are not generalizable and, therefore, not research. Many classroom projects, if not intended to be published, are also not considered research. Many quality improvement or program evaluation studies are not research.

The following documents were reviewed and acknowledged for use as part of this submission. Only the documents listed below may be used in the research. Please access and print the files in the Notes \& Attachments section of your approved protocol.

- IBC Waiver Emails.pdf

WVU IRB acknowledgement of protocol 1910741290 will expire on 10/23/2024.

Protocol \#: 1910741290

FWA: 00005078

IORG: 0000194
Phone: 304-293-7073

Fax: 304-293-3098

Email: IRB@mail.wvu.edu 
If the study is to continue beyond the expiration date, a new application must be submitted to the WVU IRB. It is your responsibility to submit your protocol for review.

The Office of Research Integrity and Compliance will be glad to provide assistance to you throughout the research process. Please feel free to contact us by phone, at 304.293 .7073 or by email at IRB@mail.wvu.edu.

Sincerely,

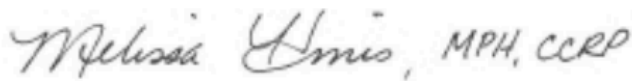

Melissa Himes

IRB Administrator

Protocol \#: 1910741290

FWA: 00005078

IORG: 0000194
Phone: $304-293-7073$

Fax: 304-293-3098

Email: IRB@mail.wvu.edu 
APPENDIX B-DATA RESULTS

\begin{tabular}{|c|c|c|c|c|c|}
\hline Material & Tooth & $\begin{array}{l}\text { Becker ARI } \\
\text { Artun }\end{array}$ & $\begin{array}{l}\text { Becker ARI } \\
\text { modified }\end{array}$ & $\begin{array}{l}\text { Kao ARI } \\
\text { Artun }\end{array}$ & $\begin{array}{l}\text { Kao ARI } \\
\text { modified }\end{array}$ \\
\hline Bracepaste & 1 & $\mathrm{x}$ & 1 & $\mathrm{x}$ & 2 \\
\hline Bracepaste & 2 & $\mathrm{x}$ & 3 & $\mathrm{x}$ & 4 \\
\hline Bracepaste & 3 & $\mathrm{x}$ & 4 & $\mathrm{x}$ & 4 \\
\hline Bracepaste & 4 & $\mathrm{x}$ & 4 & $\mathrm{x}$ & 4 \\
\hline Bracepaste & 5 & $\mathrm{x}$ & 1 & $\mathrm{x}$ & 1 \\
\hline Bracepaste & 6 & $\mathrm{x}$ & 1 & $\mathrm{x}$ & 2 \\
\hline Bracepaste & 7 & $\mathrm{x}$ & 2 & $\mathrm{x}$ & 2 \\
\hline Bracepaste & 8 & 2 & 3 & 2 & 3 \\
\hline Bracepaste & 9 & 1 & 4 & 3 & 4 \\
\hline Bracepaste & 10 & 2 & 3 & 2 & 3 \\
\hline Bracepaste & 11 & 1 & 4 & 2 & 4 \\
\hline Bracepaste & 12 & 2 & 1 & 2 & 1 \\
\hline Bracepaste & 13 & 1 & 3 & 2 & 3 \\
\hline Bracepaste & 14 & 2 & 1 & 3 & 2 \\
\hline Bracepaste & 15 & 1 & 3 & 2 & 3 \\
\hline Bracepaste & 16 & 1 & 2 & 2 & 4 \\
\hline Bracepaste & 17 & 0 & 5 & 0 & 5 \\
\hline Bracepaste & 18 & 2 & 1 & 3 & 1 \\
\hline Bracepaste & 19 & 1 & 0 & 3 & 0 \\
\hline Bracepaste & 20 & 2 & 4 & 2 & 4 \\
\hline Bracepaste & 21 & $\mathrm{x}$ & $\mathrm{x}$ & $\mathrm{x}$ & $\mathrm{x}$ \\
\hline Bracepaste & 22 & 3 & 1 & 3 & 1 \\
\hline Bracepaste & 23 & 1 & 2 & 2 & 2 \\
\hline Bracepaste & 24 & 2 & 2 & 2 & 2 \\
\hline Bracepaste & 25 & 1 & 3 & 2 & 3 \\
\hline Bracepaste & 26 & 3 & 0 & 1 & 4 \\
\hline Bracepaste & 27 & 2 & 2 & 3 & 1 \\
\hline Bracepaste & 28 & 2 & 1 & 2 & 1 \\
\hline Bracepaste & 29 & 1 & 4 & 3 & 4 \\
\hline Bracepaste & 30 & 1 & 2 & 1 & 3 \\
\hline Bracepaste & 31 & 2 & 1 & 2 & 1 \\
\hline Bracepaste & 32 & 1 & 4 & 1 & 5 \\
\hline Bracepaste & 33 & $\mathrm{x}$ & $\mathrm{x}$ & $\mathrm{x}$ & $\mathrm{x}$ \\
\hline Bracepaste & 34 & 1 & 4 & 1 & 5 \\
\hline Bracepaste & 35 & 2 & 2 & 2 & 1 \\
\hline Bracepaste & 36 & 2 & 1 & 2 & 1 \\
\hline Bracepaste & 37 & 1 & 4 & 3 & 4 \\
\hline Bracepaste & 38 & 2 & 3 & 2 & 3 \\
\hline Bracepaste & 39 & 1 & 4 & 2 & 3 \\
\hline Bracepaste & 40 & 2 & 2 & 2 & 2 \\
\hline Bracepaste & 41 & 2 & 4 & 3 & 4 \\
\hline Bracepaste & 42 & 1 & 2 & 2 & 2 \\
\hline
\end{tabular}




\begin{tabular}{|c|c|c|c|c|c|}
\hline MATERIAL & TOOTH & $\begin{array}{l}\text { Becker ARI } \\
\text { Artun }\end{array}$ & $\begin{array}{l}\text { Becker ARI } \\
\text { modified }\end{array}$ & $\begin{array}{l}\text { Kao ARI } \\
\text { Artun }\end{array}$ & $\begin{array}{l}\text { Kao ARI } \\
\text { modified }\end{array}$ \\
\hline Transbond & 1 & $\mathrm{x}$ & 4 & $\mathrm{x}$ & 4 \\
\hline Transbond & 2 & $\mathrm{x}$ & $\mathrm{x}$ & $\mathrm{x}$ & $\mathrm{x}$ \\
\hline Transbond & 3 & $\mathrm{x}$ & 1 & $\mathrm{x}$ & 1 \\
\hline Transbond & 4 & $\mathrm{x}$ & $\mathrm{x}$ & $\mathrm{x}$ & $\mathrm{x}$ \\
\hline Transbond & 5 & $\mathrm{x}$ & 4 & $\mathrm{x}$ & 4 \\
\hline Transbond & 6 & $\mathrm{x}$ & 1 & $\mathrm{x}$ & 1 \\
\hline Transbond & 7 & $\mathrm{x}$ & 2 & $\mathrm{x}$ & 1 \\
\hline Transbond & 8 & $\mathrm{x}$ & 1 & $\mathrm{x}$ & 1 \\
\hline Transbond & 9 & $\mathrm{x}$ & $\mathrm{x}$ & $\mathrm{x}$ & $\mathrm{x}$ \\
\hline Transbond & 10 & $\mathrm{x}$ & 1 & $\mathrm{x}$ & 1 \\
\hline Transbond & 11 & $\mathrm{x}$ & $\mathrm{x}$ & $\mathrm{x}$ & $\mathrm{x}$ \\
\hline Transbond & 12 & 2 & 2 & 2 & 2 \\
\hline Transbond & 13 & 0 & 5 & 1 & 5 \\
\hline Transbond & 14 & 2 & 1 & 2 & 1 \\
\hline Transbond & 15 & $\mathrm{x}$ & $\mathrm{x}$ & $\mathrm{x}$ & $\mathrm{x}$ \\
\hline Transbond & 16 & 2 & 1 & 2 & 1 \\
\hline Transbond & 17 & $\mathrm{x}$ & $\mathrm{x}$ & $\mathrm{x}$ & $\mathrm{x}$ \\
\hline Transbond & 18 & 0 & 4 & 2 & 4 \\
\hline Transbond & 19 & 2 & 1 & 3 & 1 \\
\hline Transbond & 20 & 0 & 5 & 1 & 5 \\
\hline Transbond & 21 & 0 & 5 & 1 & 5 \\
\hline Transbond & 22 & 0 & 5 & 1 & 5 \\
\hline Transbond & 23 & 2 & 3 & 1 & 4 \\
\hline Transbond & 24 & 2 & 1 & 2 & 2 \\
\hline Transbond & 25 & 2 & 1 & 2 & 1 \\
\hline Transbond & 26 & $\mathrm{x}$ & $\mathrm{x}$ & $\mathrm{x}$ & $\mathrm{x}$ \\
\hline Transbond & 27 & 1 & 4 & 1 & 4 \\
\hline Transbond & 28 & 2 & 1 & 3 & 1 \\
\hline Transbond & 29 & 0 & 5 & 0 & 5 \\
\hline Transbond & 30 & 2 & 4 & 1 & 4 \\
\hline Transbond & 31 & 2 & 2 & 2 & 2 \\
\hline Transbond & 32 & 2 & 1 & 3 & 2 \\
\hline Transbond & 33 & 2 & 1 & 2 & 1 \\
\hline Transbond & 34 & $\mathrm{x}$ & $\mathrm{x}$ & $\mathrm{x}$ & $\mathrm{x}$ \\
\hline Transbond & 35 & 1 & 4 & 1 & 4 \\
\hline Transbond & 36 & 0 & 5 & 1 & 5 \\
\hline Transbond & 37 & $\mathrm{x}$ & $\mathrm{x}$ & $\mathrm{x}$ & $\mathrm{x}$ \\
\hline Transbond & 38 & $\mathrm{x}$ & $\mathrm{x}$ & $\mathrm{x}$ & $x$ \\
\hline Transbond & 39 & 1 & 4 & 1 & 5 \\
\hline Transbond & 40 & 2 & 1 & 2 & 1 \\
\hline Transbond & 41 & 0 & 5 & 0 & 5 \\
\hline Transbond & 42 & 2 & 1 & 1 & 2 \\
\hline
\end{tabular}




\begin{tabular}{|c|c|c|c|c|c|}
\hline MATERIAL & TOOTH & $\begin{array}{l}\text { BECKER \#1 } \\
\text { READ }\end{array}$ & BECKER \#2 READ & $\begin{array}{l}\text { KAO \#1 } \\
\text { READ }\end{array}$ & KAO \#2 READ \\
\hline Bracepaste & 1 & $\mathrm{C}$ & C & C & C \\
\hline Bracepaste & 2 & C & C & C & C \\
\hline Bracepaste & 3 & $\mathrm{C}$ & C & $\mathrm{C}$ & C \\
\hline Bracepaste & 4 & C & C & C & C \\
\hline Bracepaste & 5 & B & B & B & B \\
\hline Bracepaste & 6 & C & C & C & $B$ \\
\hline Bracepaste & 7 & B & B & B & B \\
\hline Bracepaste & 8 & C & C & C & C \\
\hline Bracepaste & 10 & C & C & C & C \\
\hline Bracepaste & 11 & $B$ and $D$ & B & B & B \\
\hline Bracepaste & 12 & C & C & B & B \\
\hline Bracepaste & 13 & C & C & C & C \\
\hline Bracepaste & 15 & B & B & B & B \\
\hline Bracepaste & 16 & C & B & C & B \\
\hline Bracepaste & 18 & $B$ & $B$ & $B$ & $B$ \\
\hline Bracepaste & 19 & $B$ & $B$ & $B$ & $B$ \\
\hline Bracepaste & 20 & C & C & C & C \\
\hline Bracepaste & 23 & C & $B$ & $B$ & B \\
\hline Bracepaste & 24 & A & A & B & A \\
\hline Bracepaste & 25 & B & B & B & B \\
\hline Bracepaste & 28 & C & B & B & B \\
\hline Bracepaste & 30 & C & B & $B$ & $B$ \\
\hline Bracepaste & 31 & B & B & B & B \\
\hline Bracepaste & 32 & B & A & A & A \\
\hline Bracepaste & 34 & C & C & C & C \\
\hline Bracepaste & 35 & $A$ & B & $B$ & B \\
\hline Bracepaste & 36 & A & A & A & $A$ \\
\hline Bracepaste & 38 & A & A & A & $A$ \\
\hline Bracepaste & 39 & B & B & B & $A$ \\
\hline Bracepaste & 40 & C & C & C & $C$ \\
\hline Bracepaste & 42 & C and D & C and D & C and D & C and D \\
\hline
\end{tabular}




\begin{tabular}{|c|c|c|c|c|c|}
\hline MATERIAL & TOOTH & $\begin{array}{l}\text { BECKER \#1 } \\
\text { READ }\end{array}$ & $\begin{array}{l}\text { BECKER \#2 } \\
\text { READ }\end{array}$ & KAO \#1 READ & $\begin{array}{l}\text { KAO \#2 } \\
\text { READ }\end{array}$ \\
\hline Transbond & 1 & $\mathrm{C}$ & $\mathrm{C}$ & $\mathrm{C}$ & $\mathrm{C}$ \\
\hline Transbond & 2 & $\mathrm{X}$ & $\mathrm{X}$ & $\mathrm{X}$ & $\mathrm{X}$ \\
\hline Transbond & 3 & $\mathrm{C}$ & $\mathrm{C}$ & $\mathrm{C}$ & $\mathrm{C}$ \\
\hline Transbond & 4 & $\mathrm{X}$ & $\mathrm{X}$ & $\bar{X}$ & $\mathrm{X}$ \\
\hline Transbond & 5 & B & B & B & B \\
\hline Transbond & 6 & B & B & B & B \\
\hline Transbond & 7 & $\mathrm{C}$ & $\mathrm{C}$ & $\mathrm{C}$ & $\mathrm{C}$ \\
\hline Transbond & 8 & $\mathrm{C}$ & $\bar{C}$ & $\mathrm{C}$ & $\bar{C}$ \\
\hline Transbond & 9 & $\mathrm{X}$ & $\mathrm{X}$ & $\mathrm{X}$ & $\mathrm{X}$ \\
\hline Transbond & 10 & B & $\mathrm{B}$ & B & B \\
\hline Transbond & 12 & $\mathrm{C}$ & $\mathrm{C}$ & $\mathrm{C}$ & $\mathrm{C}$ \\
\hline Transbond & 14 & $\mathrm{C}$ & $\mathrm{C}$ & $\mathrm{C}$ & $\mathrm{C}$ \\
\hline Transbond & 16 & $\mathrm{~B}$ & A & B & $\mathrm{A}$ \\
\hline Transbond & 23 & $\mathrm{C}$ & $\mathrm{B}$ and $\mathrm{D}$ & $\mathrm{C}$ & $\mathrm{C}$ \\
\hline Transbond & 24 & $\mathrm{~A}$ & A & $\mathrm{A}$ & $\mathrm{B}$ \\
\hline Transbond & 25 & B & B & B & B \\
\hline Transbond & 27 & B & $\mathrm{C}$ & B & $\mathrm{C}$ \\
\hline Transbond & 30 & B & B & B & B \\
\hline Transbond & 31 & B & B & B & A \\
\hline Transbond & 33 & $\mathrm{C}$ & $\mathrm{C}$ & $\mathrm{C}$ & $\mathrm{C}$ \\
\hline Transbond & 35 & $\mathrm{~B}$ and $\mathrm{D}$ & $\mathrm{B}$ and $\mathrm{D}$ & $\mathrm{C}$ & $\mathrm{C}$ \\
\hline Transbond & 39 & B & B & B & B \\
\hline Transbond & 40 & $\mathrm{C}$ & $\mathrm{C}$ & $\mathrm{C}$ & $\mathrm{C}$ \\
\hline Transbond & 42 & B & B & B & B \\
\hline
\end{tabular}

